University of Massachusetts Amherst

ScholarWorks@UMass Amherst

Masters Theses

Dissertations and Theses

August 2019

\title{
Electrospinning Nanofibers from Chitosan-Hyaluronic Acid Complex Coacervates
}

Juanfeng Sun

University of Massachusetts Amherst

Follow this and additional works at: https://scholarworks.umass.edu/masters_theses_2

Part of the Chemical Engineering Commons

\section{Recommended Citation}

Sun, Juanfeng, "Electrospinning Nanofibers from Chitosan-Hyaluronic Acid Complex Coacervates" (2019). Masters Theses. 800.

https://doi.org/10.7275/14179920 https://scholarworks.umass.edu/masters_theses_2/800

This Open Access Thesis is brought to you for free and open access by the Dissertations and Theses at ScholarWorks@UMass Amherst. It has been accepted for inclusion in Masters Theses by an authorized administrator of ScholarWorks@UMass Amherst. For more information, please contact scholarworks@library.umass.edu. 


\title{
ELECTROSPINNING NANOFIBERS FROM CHITOSAN-HYALURONIC ACID COMPLEX COACERVATES
}

\author{
A Thesis Presented by \\ JUANFENG SUN \\ Submitted to the Graduate School of the \\ University of Massachusetts Amherst in partial fulfillment \\ of the requirements for the degree of \\ MASTER OF SCIENCE IN CHEMICAL ENGINEERING
}

May 2019

Department of Chemical Engineering 
(C) Copyright 2019

Juanfeng Sun All Rights Reserved. 


\title{
ELECTROSPINNING NANOFIBERS FROM CHITOSAN-HYALURONIC ACID COMPLEX COACERVATES
}

\author{
A Thesis Presented by
}

JUANFENG SUN

Approved as to style and content by:

Sarah L. Perry, Member

Jessica D. Schiffman, Member

Wei Fan, Member

John Klier, Department Head Chemical Engineering Department 


\begin{abstract}
ELECTROSPINNING NANOFIBERS FROM CHITOSAN-HYALURONIC ACID COMPLEX COACERVATES
\end{abstract}

MAY 2019

JUANFENG SUN

\title{
B.S., UNIVERSITY OF NEW HAMPSHIRE
}

\section{M.S.Ch.E., UNIVERSITY OF MASSACHUSETTS-AMHERST}

Directed by: Professors Jessica D. Schiffman \& Sarah L. Perry

Electrospun nanofibers have been used for many applications, but a reliance on organic solvents limits their use in biomedical fields. In this study, we successfully electrospun nanofibers from aqueous chitosan-hyaluronic acid complex coacervates. We studied how solvent' properties affected the average nanofiber diameter by using pure water as a solvent versus ethanol-water solutions. Experimentally, we investigated the effect of electrospinning apparatus parameters, such as how the applied voltage affected fiber formation and morphology. The smallest average nanofiber diameter was determined to be around $115 \pm 30 \mathrm{~nm}$ when 3 wt $\%$ ethanol coacervate samples were electrospun using the applied voltage of 24 $\mathrm{kV}$. Linear viscoelastic measurements were used to study the rheological characterization of complex coacervate with different salt concentrations and 
cosolvents (e.g., ethanol weight percent). Chitosan-hyaluronic acid nanofibers hold potential in biomedical applications such as wound dressing, tissue engineering, would healing scaffolds. 


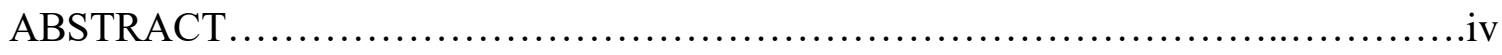

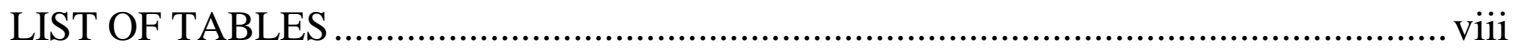

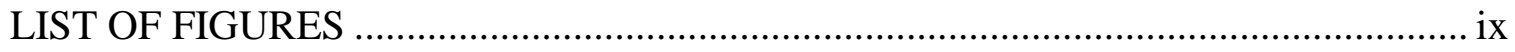

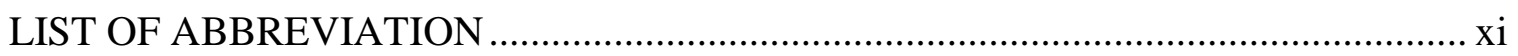

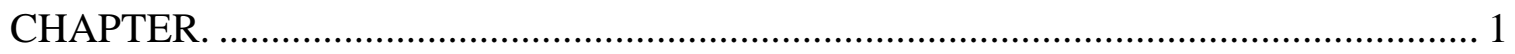

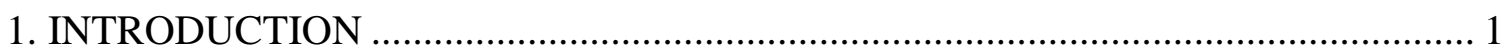

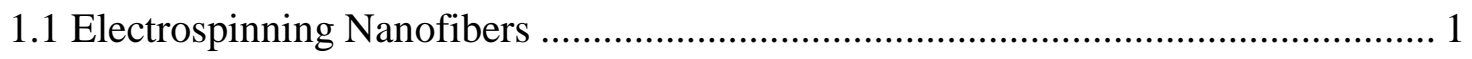

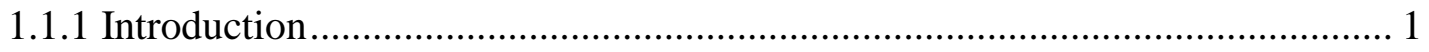

1.1.2 Electrospinning Process .............................................................................. 1

1.1.3 Rheological Characterization of Precursor Solutions ........................................ 2

1.2 Synthetic Polymers vs. Natural Polymers............................................................... 3

1.2.1 Synthetic Polymers ……………………..................................................... 3

1.2.2 Natural Polymers ………………………………....................................... 4

1.3 Chitosan and Hyaluronic Acid........................................................................ 4

1.3.1 Electrospinning Chitosan Nanofibers ............................................................... 5

1.3.2 Electrospinning Hyaluronic Acid Nanofibers ..................................................... 6

1.4 Polyelectrolyte Complex................................................................................. 7

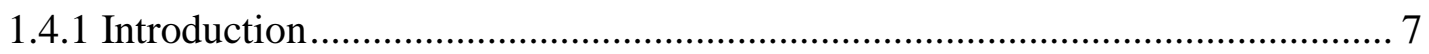

1.4.2 Characterizing Coacervate Phase Behavior ........................................................ 7

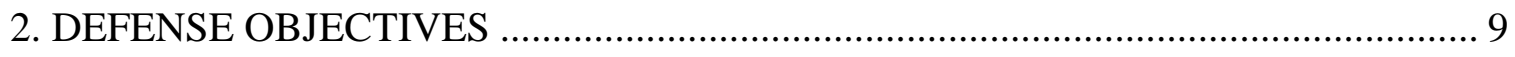

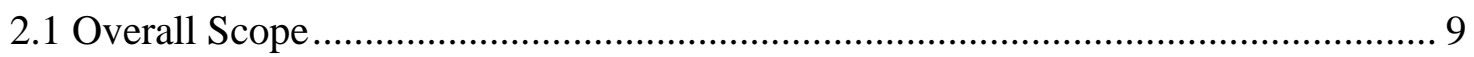

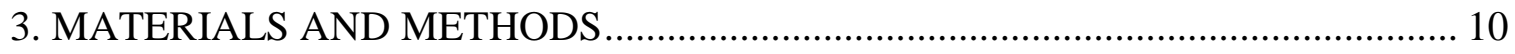

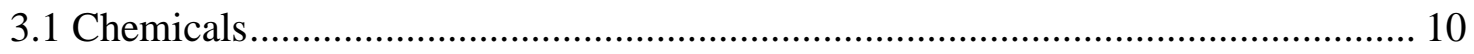

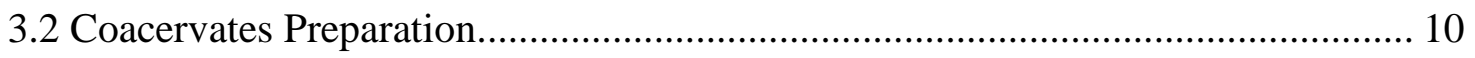

3.3 Turbidity and Optical Microscopy .................................................................... 11 
3.4 Rheological Characterization of Complex Coacervates .................................... 11

3.5 Electrospinning Aqueous Complex Coacervates into PEC Nanofibers ................ 12

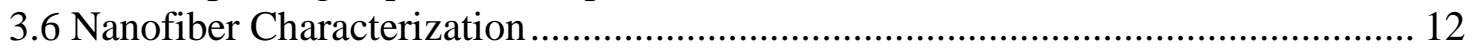

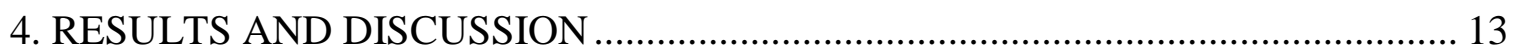

4.1 CH-HA Coacervate Formation and Characterization ......................................... 13

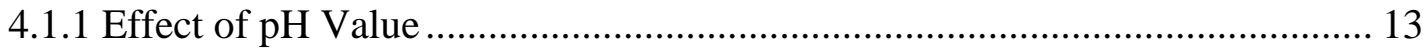

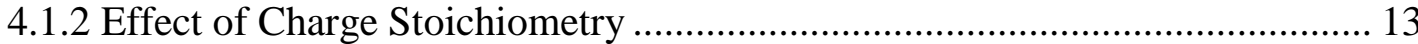

4.1.3 Effect of Salt Concentration................................................................. 14

4.2 Electrospinning CH-HA Nanofibers ........................................................ 15

4.3 Rheological Characterization of Chitosan-Hyaluronic Acid Coacervates............. 19

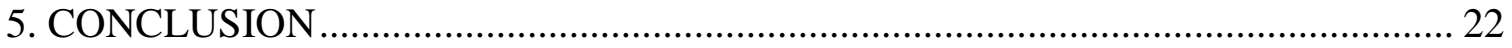

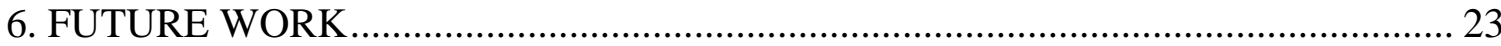

APPENDIX: RHEOLOGICAL CHARACTERIZATION OF CHITOSANHYALURONIC ACID COACERVATES .....................................24

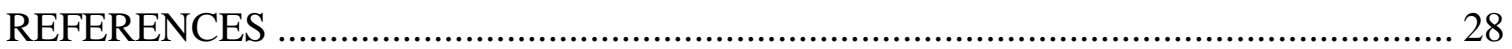




\section{LIST OF TABLES}

$\begin{array}{lll}\text { Table } & \text { Page }\end{array}$

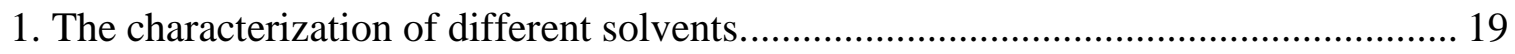




\section{LIST OF FIGURES}

Figure

Page

Figure 1. The schematic displays an electrospinning apparatus, which is composed of a spinneret, a high voltage supply, and a collector 2

Figure 2. (a) Plot of specific viscosity vs concentration of chitosan $(148,000 \mathrm{~g} / \mathrm{mol})$ in

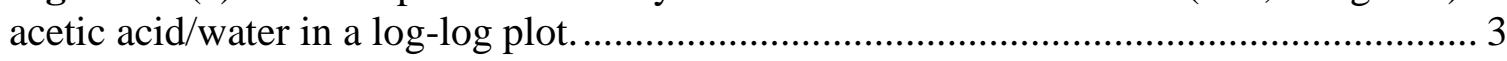

Figure 3. Molecular structures of chitosan $(\mathrm{CH})$ and hyaluronic acid (HA). .................. 5

Figure 4. Schematic of the formation of polyelectrolyte complex. ............................... 7

Figure 5. Schematic depiction of a phase diagram (binodal curve) for complex coacervation, as a function of total salt concentration and total polymer concentration.... 8

Figure 6. pH titration profiles for HA (234.4 kDa) and $\mathrm{CH}(260 \mathrm{kDa}, 83 \% \mathrm{DD})$ in $0.5 \mathrm{M}$ $\mathrm{NaCl}$. 13

Figure 7. (a) A plot of turbidity as a function of the mole fraction of the chitosan for coacervates of chitosan and hyaluronic acid at different salt concentrations 15

Figure 8. (a) SEM micrographs and (b) plots of the corresponding average fiber diameter as a function of voltage for $0 \mathrm{wt} \%$ ethanol. 16

Figure 9. (a) SEM micrographs and (b) plots of the corresponding average fiber diameter for different cosolvent concentrations. 17

Figure 10. (a) SEM micrographs (b) plots of the corresponding average fiber diameter as a function of voltage for $3 \mathrm{wt} \%$ ethanol. 18

Figure 11. Frequency sweep data for ethanol samples prepared at $300 \mathrm{mM}$ (black), 400 $\mathrm{mM}$ (red), $500 \mathrm{mM}$ (green), $600 \mathrm{mM}$ (blue) and 650/700 mM (purple) $\mathrm{NaCl}$.

Figure 12. Plots of (a) zero-shear viscosity of $\mathrm{CH}-\mathrm{HA}$ coacervates as a function of salt and ethanol content, and (b) the corresponding relaxation spectra for coacervates prepared at $600 \mathrm{mM} \mathrm{NaCl}$ over a range of ethanol concentrations. 21

Figure 13. Plots of relaxation spectra for $\mathrm{CH}-\mathrm{HA}$ coacervates prepared at $300 \mathrm{mM}, 400$ $\mathrm{mM} 500 \mathrm{mM} 600 \mathrm{mM} 700 \mathrm{mM} \mathrm{NaCl}$ over a range of ethanol concentrations............24

Figure 14. Plots of the time-salt superposition of frequency sweep data for CH-HA complex coacervates ( $300 \mathrm{mM}$ to $700 \mathrm{mM} \mathrm{NaCl}$ ), shifted with respect to the $300 \mathrm{mM}$ ' as prepared' data 25

Figure 15. Frequency sweep data for $\mathrm{CH}-\mathrm{HA}$ methanol cosolvent.. 26 
Figure 16. Plots of (a) zero-shear viscosity of $\mathrm{CH}-\mathrm{HA}$ coacervates as a function of salt and methanol content, and (b) (c) (d) the corresponding relaxation spectra for coacervates prepared at $500 \mathrm{Mm} 600 \mathrm{mM} 700 \mathrm{mM} \mathrm{NaCl}$ over a range of methanol concentrations....27 


\section{LIST OF ABBREVIATION}

$\mathrm{CH}$ : chitosan

DI water: deionized water

HA: hyaluronic acid

$\mathrm{HCl}$ : hydrochloric acid

$\mathrm{NaCl}$ : sodium chloride

$\mathrm{NaOH}$ : sodium hydroxide

PEC: polyelectrolyte complex

SEM: scanning electron microscopy

wt\%: weight percent 


\section{CHAPTER 1}

\section{INTRODUCTION}

\subsection{Electrospinning Nanofibers}

\subsubsection{Introduction}

Electrospinning is considered one of the most efficient techniques for producing continuous polymer fibers with diameters ranging from the nano to the micrometer scale. Their advantages include being low cost, with a high production rate and they can be scaled up for manufacuring. ${ }^{1,2}$ Electrospun fibers have outstanding intrinsic structure-properties, such as: high porosity and specific surface area, interconnectivity, and a large surface-tovolume ratio, which make them excellent materials for a wide range of applications, especially for medical applications, ${ }^{2-4}$ such as tissue templates, ${ }^{2-5}$ artificial organs, ${ }^{5}$ nanofibrous scaffolds, ${ }^{2,5,6}$ drug delivery, ${ }^{2,4,6-8}$ wound dressings, ${ }^{4,5,7-9}$ etc. Furthermore, electrospinning can be used to fabricate nonwoven fibers from a wide range of materials, such as synthetic and natural polymers. ${ }^{4}$

\subsubsection{Electrospinning Process}

A conventional electrospinning apparatus includes a spinneret, a high voltage power supply, and a collector, Figure 1. During electrospinning, a precursor solution is loaded into the spinneret and forced through a narrow orifice to form dependent droplets at the needle tip. As the voltage increases, the repulsive force pulls out the solution into a Taylor cone. ${ }^{10}$ Once the voltage reaches a critical value, the repulsive force overcomes the surface tension of the solution and a liquid jet is ejected from the Taylor cone to the collector. During this process, the fiber jet experiences whipping and bending to allow the 
solvent to evaporate before fibers are accumulated on the collector, ${ }^{3}$ and the whole process usually takes place in milliseconds. ${ }^{11,12}$

During the electrospinning process, there are many parameters that impact fiber formation and their morphology, such as precursor solution (concentration, conductivity, surface tension, viscosity, and appropriate polymer and solvents); processing variables (distance from the nozzle to the collector, initial jet radius, applied voltage, and flow rate of the solution); and environmental conditions (temperature and humidity). ${ }^{3,13}$ These different processing parameters can be used to control the fabrication of fibers. For example: increasing the voltage or decreasing the solution flow rate will tend to decrease the diameter of the resulting fibers. ${ }^{14}$

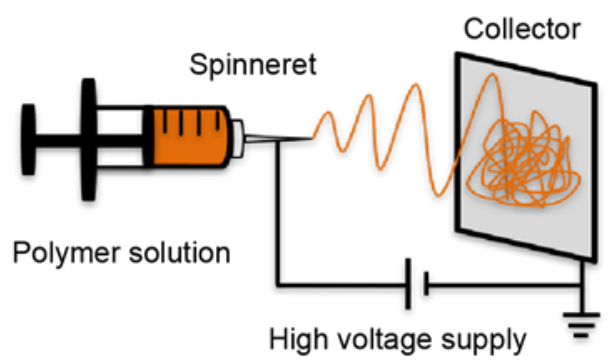

Figure 1. The schematic displays an electrospinning apparatus, which is composed of a spinneret, a high voltage supply, and a collector. Usually, an advancement pump is used to regulate the flow rate of the polymeric solution. ${ }^{25}$

\subsubsection{Rheological Characterization of Precursor Solutions}

The properties of the precursor solution are the parameters that tend to have the most significant effect on the formation of fibers. Empirical observations show that a minimum polymer concentration is required for fiber formation to occur. ${ }^{15-19}$ Below this critical value, electrospraying of droplets will occur instead of electrospinning. ${ }^{17,18}$ It has been reported that the polymer concentration must be at least 2 to 2.5 times the entanglement concentration $\left(c_{e}\right)$ to form continuous defect-free fibers. However, polymers like polyamides can form hydrogen-bond or charge repulsion intra/intermolecularly in 
solvents, so the polymer-polymer interactions become more important to be considered. ${ }^{17,18}$ For example, a medium molecular weight $(148,000 \mathrm{~g} / \mathrm{mol})$ chitosan solution would have a viscosity over 170,000 P because of the rigid backbone, which would be impossible to spin (Figure 2). ${ }^{17}$ Therefore, It is important to understand the rheological behavior of the polymer solution to determine its electrospinnability and investigate alternative mothods to spin polyelectrolyte containing solutions.
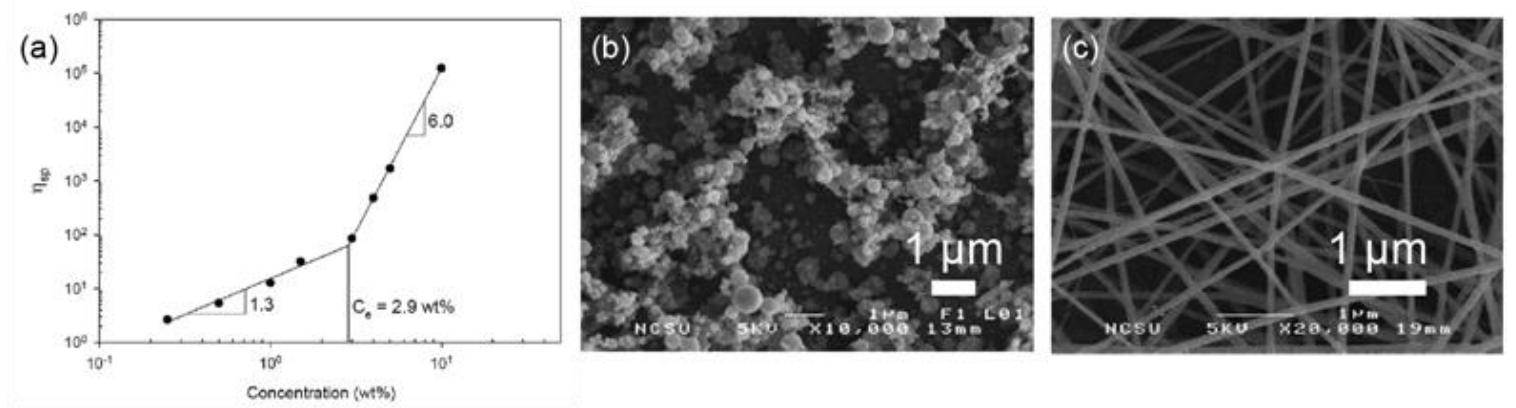

Figure 2. (a) Plot of specific viscosity vs concentration of chitosan $(148,000 \mathrm{~g} / \mathrm{mol})$ in acetic acid/water in a log-log plot. The entanglement concentration $\left(\mathrm{C}_{\mathrm{e}}\right)$ was determined to be $2.9 \mathrm{wt} \%$ from the figure. (b) Scanning electron microscope (SEM) micrographs of "electrosprayed" beads from an acetic acid/water solution with $3 \mathrm{wt} \%$ chitosan, and (c) electrospun fiber from solution made of 8: 9 chitosan: poly(ethylene oxide) blend in acetic acid/water solution with $3.4 \mathrm{wt} \%$ total polymer. ${ }^{17}$

\subsection{Synthetic Polymers vs. Natural Polymers}

\subsubsection{Synthetic Polymers}

For successful application, the nanofibers should have suitable physical and biological properties that match the desired requirements. Synthetic polymers have more advantages over natural polymers in physical properties; the strength and durability of them and they can be designed to give a wide range predictable properties. ${ }^{4}$ There are synthetic polymers that have been electrospun into nanofibers for biomedical applications, such as poly(glycolic acid) (PGA),${ }^{20}$ polyurethane,${ }^{21}$ poly(vinyl alcohol),${ }^{22,23}$ poly(ethylene oxide) 
(PEO), ${ }^{24}$ poly(4-styrene sulfonate sodium salt) (PSS) and poly(diallyldimethyl ammonium chloride) (PDADMAC), ${ }^{25}$ etc.

\subsubsection{Natural Polymers}

Electrospinning of biopolymers (e.g., alginate, ${ }^{26,27}$ cellulose,${ }^{28}$ gelatin, ${ }^{29}$ etc. $)$ has drawn great interest since biopolymers tend to have lower toxicity and immunogenicity, are derived from renewable resources (crustacean shells, wood, etc.), and have a higher biocompatibility compared to many synthetic polymers. ${ }^{30}$ It has been reported that a large number of biopolymers such as proteins $s^{29,31,32}$ and polysaccharides ${ }^{33,34}$ can be fabricated into nanofibers by electrospinning. Specially, the polysaccharides chitosan and hyaluronic acid have been electrospun for localized drug deliver. ${ }^{3,17,34-36}$

\subsection{Chitosan and Hyaluronic Acid}

Both chitosan and hyaluronic acid have drawn attention from the field of biomaterials due to their desirable properties such as biocompatibility, and biodegradability. ${ }^{31,37,38}$ For example: Chitosan based nanofibers can be used in tissue engineering, filtration, enzyme immobilization, drug delivery, and wound dressing $;{ }^{39-44}$ the applications of the hyaluronic acid based nanofibers are in areas such as: drug delivery, dermatology, tissue engineering, and medical implants. ${ }^{45-48}$ Electrospinning polymer blends might be able to combine different polymers for desired materials properties, ${ }^{4}$ thus, electrospun chitosan-hyaluronic acid fiber mats would have potential application in wounding dressing due to their specific properties that promote would healing, such as chitosan has antibacterial and hemostatic activity and hyaluronic acid can promote different type of wounds: heavily exuding wounds, dry wounds. ${ }^{3}$ 
Chitosan is produced by the deacetylation of crab/insect shells and is the second most abundant polysaccharide after cellulose. Chitosan is a cationic biopolymer composed of 2-acetamide-2-deoxy- $\beta$-D-glucopyranose and 2-amino-2deoxy- $\beta$-D-glucopyranose (Figure 2) ${ }^{17,49,50}$ The pKa of chitosan is around 6.3 due to the amino group of glucosamine residues, but varies depending on the level of deacetylation that makes chitosan tend to have blocky regions of charge/not charge; chitosan will be positively charged in acidic solutions, which allows for electrostatic interaction with negatively charged molecules. ${ }^{51-53}$

On the other hand, hyaluronic acid is negatively charged when the $\mathrm{pH}$ value is above its pKa of 2.9. ${ }^{52,53}$ Hyaluronic acid can be sourced from a broad range of tissue, animals and its structure ${ }^{56}$ It is composed of an alternating disaccharide unit of $\alpha-1,4-\mathrm{D}$-glucuroronic acid and $\beta-1,3-\mathrm{N}$-acetyl-D-glucosamine (Figure 3). ${ }^{27,30,53-}$ 55 However, electrospinning these two polysaccharides has historically been challenging due to the long-range electrostatic interactions and high viscous solutions at low polymer concentrations. ${ }^{35,57}$

Chitosan $(\mathrm{CH})$

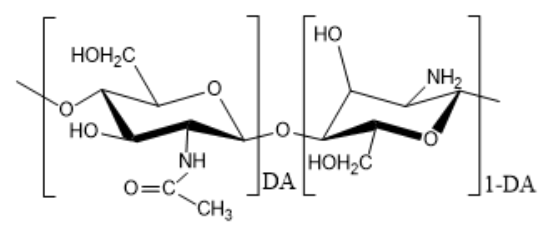

Hyaluronic Acid (HA)

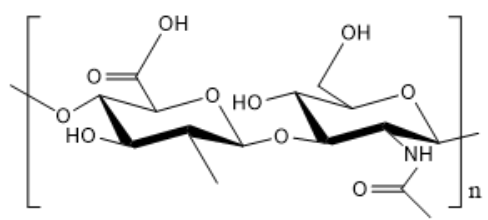

Figure 3. Molecular structures of chitosan $(\mathrm{CH})$ and hyaluronic acid (HA). The degree of acetylation (DA) of chitosan is proportional to the number of acetylglucosamine units in the polymer.

\subsubsection{Electrospinning Chitosan Nanofibers}

Chitosan is soluble in most aqueous acids because protonation of the amino group facilitates dissolution in water. However, as described earlier, repulsive charge-charge interactions along the polymer backbone and between polymers can make the formation of 
continuous fibers during electrospinning challenging. ${ }^{57-59}$ Previous reports were able to successfully electrospin chitosan fibers by using harsh acidic solvents and/or polymer mixtures. For example: 1) Dissolving chitosan in trifluoroacetic acid (TFA) allows for the substitution of TFA as the counterion for the charged amino group of chitosan. ${ }^{60-62} 2$ ) Mixing chitosan with other linear polymers (e.g. protein, ${ }^{34,63}$ or syntenic polymers ${ }^{64,65}$ ) to reduce the free amino groups by forming intermolecular interactions with the substances, instead between chitosan molecules. 3) Derivatives of chitosan (e.g. hexanoyl chitosan, ${ }^{66}$ $\mathrm{N}$-carboxyethyl chitosan (N-CECS), ${ }^{67,68}$ etc.) allow for improved solubility and thus spinnability. Furthermore, most of these fibers are not chemically stable without further crosslinking.

\subsubsection{Electrospinning Hyaluronic Acid Nanofibers}

Another polysaccharide, hyaluronic acid forms high viscous solutions even at low concentration due to its long-range electrostatic interactions and the presence of counter ions, which hinders the electrospinning process. ${ }^{35}$ While solubility is not as significant an issue for hyaluronic acid as compared to chitosan, the issue of reaching the critical chain entanglement concentration to successfully electrospin remains. There are literature reports of electrospinning hyaluronic acid blended with uncharged polymers, including collagen and gelatin. ${ }^{69-71}$ It has been successfully demonstrated by attaching an air blowing feature to the conventional electrospinning system to have both electrical force and an air-blowing shear force to fabricate hyaluronic acid nanofibers. ${ }^{54}$ Furthermore, electrospinning pure hyaluronic acid has been achieved in dimethylformamide (DMF), ${ }^{72}$ while blended hyaluronic acid with formic acid and DMF. ${ }^{69}$ 


\subsection{Polyelectrolyte Complex}

\subsubsection{Introduction}

Complex coacervation is a liquid-liquid phase separation resulting from the interaction of oppositely charged polyelectrolytes in water, and results in a dense, polymer-rich liquid coacervate phase in equilibrium with a polymer-poor supernatant. ${ }^{73-76}$ Coacervation may be driven by enthalpic contributions from intermacroionic electrostatic interactions, but is dominated by entropic contributions from the release of bound counterions and the reconstructing of water upon complex formatiom. ${ }^{74-78}$ Generally, the self-assembly and phase separation behaviour of coacervates can be influenced by various parameters, such as ionic strength, $\mathrm{pH}$, stoichiometry, polymer chain length and concentration. ${ }^{73-78}$ Complex coacervation has a long history of use in fields such as: food and personal care products, ${ }^{79-82}$ encapsulation, ${ }^{83-85}$ drug deliver ${ }^{83,85,86}$ adhesive,${ }^{87,88}$ etc.

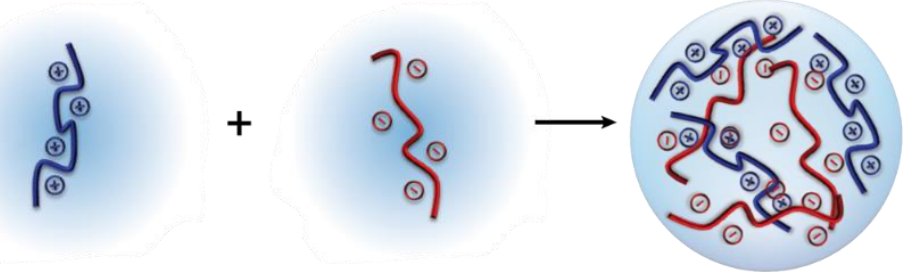

Figure 4. Schematic of the formation of polyelectrolyte complex. Aqueous solutions of polycation (blue) are mixed with solutions of polyanions (red), resulting in liquid-liquid phase separation.

\subsubsection{Characterizing Coacervate Phase Behavior}

It is important to understand the phase behavior of coacervates for coacervate-based materials. By using turbidimetry and light scattering measurements to provide qualitative information for both polymer-rich coacervate 
and the polymer-poor supernatant phase to map out the of coacervate phase behaviour. ${ }^{73}$ While there are many control parameters, out effects have focused on understanding the effect of salt on coacervate phase behaviour. Figure $\mathbf{5}$ shows a general schematic of a coacervate phase diagram: at low salt concentration, polyelectrolyte complex (PECs) are solid; with increasing salt concentration, the screening affects strength of the electrostatic interaction between polyelectrolytes, which leads to a liquid-liquid phase separation following the tie lie; above the critical point, there will just be single-phase due to large number of salts present in system the disfavors the release of counterions. ${ }^{74,89-91}$ Furthermore, binodal curve shows increase the total polymer concentration does not end up increase the polymer concentration in the coacervate phase due to the effects of salt concentration in the system as well. ${ }^{76}$

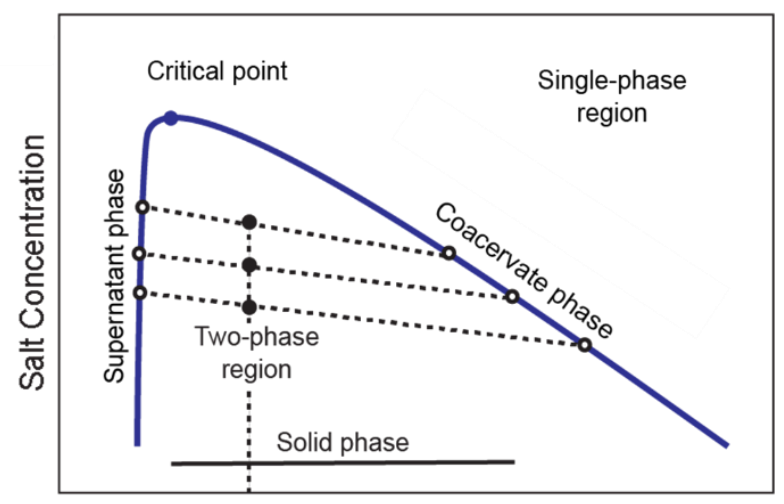

Polymer Concentration

Figure 5. Schematic depiction of a phase diagram (binodal curve) for complex coacervation, as a function of total salt concentration and total polymer concentration. Solid circles indicate the as-prepared samples, which phase separate along the dashed tielines to form a polymer-rich coacervate phase and a polymer-poor supernatant phase (open circles). 


\section{CHAPTER 2}

\section{DEFENSE OBJECTIVES}

\subsection{Overall Scope}

While chitosan and hyaluronic acid have been successfully electrospun, the toxic solvents used for electrospinning limit their use in biomedical applications. The "green" electrospinning of fiber mats from aqueous complex coacervates has previously been reported for synthetic polyelectrolytes ${ }^{25}$ Here, for the first time we have demonstrated the electrospinning of nanofibers from $\mathrm{CH}-\mathrm{HA}$ coacervate. The present study involves two ways to prepare the complex coacervates. In the first way, the pure water solvent system was examined. In the second way, the blended solvent (water-ethanol) was examined using 3wt $\%$, 5wt $\%$, and $8 \mathrm{wt} \%$ ethanol. Ethanol was chosen as a cosolvent because (1) ethanol is biocompatible and (2) ethanol improves solvent evaporation during the electrospinning process. Scanning electron microscopy was used to characterize the resulting fibers, while rheology was used to elucidate the properties of $\mathrm{CH}-\mathrm{HA}$ PECs. Electrospun $\mathrm{CH}-\mathrm{HA}$ fiber mat could be used in wound dressing. These "green" biopolymer nanofibers hold potential in biomedical application, such as wound dressings. 


\section{CHAPTER 3}

\section{MATERIALS AND METHODS}

\subsection{Chemicals}

Sodium hyaluronate (Lifecore Biomedical, Chaska, MN, USA) with average molecular weights of $199 \mathrm{kDa}$ was filtered using a $0.22 \mu \mathrm{m}$ pore size filter (Millipore Express) prior to use. Chitosan (Sigma-Aldrich with $75-85 \%$ deacetylated and $50-190$ $\mathrm{kDa}$ ), was filtered using $0.45 \mu \mathrm{m}$ pore size filter (Millipore Express) prior to use. ACSgrade sodium chloride $(\mathrm{NaCl})$, hydrochloric acid $(\mathrm{HCl})$, and sodium hydroxide $(\mathrm{NaOH})$ were used as received from Fisher Scientific. Deionized (DI) water was obtained from a Barnstead Nanopure Infinity water purification system (Thermo Fisher Scientific, Waltham, MA). Methanol and ethanol (ACS grade), as well as aqueous buffers ( $\mathrm{pH}=4.0$, 7.0, and 10.0) were utilized as received from Fisher Scientific.

\subsection{Coacervates Preparation}

Stocks solutions of chitosan and hyaluronic acid were prepared gravimetrically at $60 \mathrm{mM}$ on a monomer basis. An aqueous solution of $5 \mathrm{M} \mathrm{NaCl}$ was prepared gravimetrically, and all solutions were adjusted to $\mathrm{pH} 4.5$ by adding concentrated $\mathrm{HCl}$ and $\mathrm{NaOH}$ solutions. Complex coacervates were prepared by first combining a solution of the $\mathrm{NaCl}$ with water in a Falcon round bottom tube (14 mL, Fisher Scientific) and methanol or ethanol if added for alcohol-water cosolvent samples. Chitosan and hyaluronic acid were then added sequentially in a 1:1 molar ratio at a total monomer concentration of $40 \mathrm{mM}$. The mixture was vortexed for $10 \mathrm{~s}$ immediately after adding each solution to ensure 
complete mixing. Samples were then centrifuged (Sorvall Legend X1r Centrifuge, Thermo Fisher Scientific) at $2000 \mathrm{rpm}$ for $15 \mathrm{~min}$ to separate the dense coacervate phase.

\subsection{Turbidity and Optical Microscopy}

Samples for turbidity and microscopy were prepared using the same method as described in section 3.2 but at a smaller $120 \mu \mathrm{L}$ scale. Immediately after samples preparation, three $35 \mu \mathrm{L}$ replicate aliquots of each sample were pipetted into a 384-well plate (Falcon). Turbidity measurements were performed using a microplate reader (BioTek Synergy H1) at a wavelength of $562 \mathrm{~nm}$. Samples were then inspected visually using optical microscopy (EVOS XL Core) to confirm the presence or absence of phase separation, as well as the liquid or solid nature of complexes that might have formed.

\subsection{Rheological Characterization of Complex Coacervates}

Experiments were done by using a Malvern Kinexus Pro stress-controlled instrument. First, small amplitude oscillatory shear measurements were ran to determine what strain rate to use within the linear viscoelastic region, then frequency sweeps were conducted at chosen strain rates over the range of frequencies from 100 to 1 . A $20 \mathrm{~mm}$ diameter stainless steel parallel plate fixture with a solvent trap was used for rheological experiments for samples prepared at $500 \mathrm{mM}$ and $600 \mathrm{mM} \mathrm{NaCl}$; a $50 \mathrm{~mm} 2^{\circ}$ core-andplate fixture was used for samples prepared at $700 \mathrm{mM} \mathrm{NaCl}$. For each sample, the whole experiment was ran at least twice and the frequency sweep process was running at least four time to make sure solvent evaporation was neglectable. Furthermore, the trend of zeroshear viscosity changes with salt concentrations were generated, and the relaxation spectrum and modulus were used to study the longest relaxation time. All data analysis 
was conducted by using IRIS software (Interactive Rheology Information Systems Development LLC). ${ }^{72}$

\subsection{Electrospinning Aqueous Complex Coacervates into PEC Nanofibers}

Coacervates were loaded into a $5 \mathrm{~mL}$ syringe (Henke Sass Wolf, Norm-Ject Luer Lock) capped with a PrecisionGlide 22-gauge needle (Becton, Dickinson \& Co., Franklin Lakes, NJ). The syringe was secured to a PHD Ultra syringe pump (Harvard Apparatus, Plymouth Meeting, PA). Alligator clips were used to connect the positive anode of a highvoltage supply (Gamma High Voltage Research Inc., Ormond Beach, FL) to the needle, and the negative anode to a copper plate covered with aluminum foil. For all experiments, the coacervate was fed at a constant rate of $1.0 \mathrm{~mL} / \mathrm{hr}$ to test the effects of the electrospinning apparatus parameters. The ethanol-water cosolvent was explored at $0 \mathrm{wt} \%$, $3 \mathrm{wt} \%$ or $5 \mathrm{wt} \%$ while the applied voltage was changed $(18 \mathrm{kV}, 20 \mathrm{kV}, 22 \mathrm{kV}$, and $24 \mathrm{kV})$, and needle-to-collector separation distance was held constant at $12 \mathrm{~cm}$. The electrospinning apparatus was housed in an environmental chamber (CleaTech, Santa Ana, CA) at constant temperature of $24 \pm 1{ }^{\circ} \mathrm{C}$ and a relative humidity of $23-25 \%$ using a desiccant unit (Drierite, Xenia, $\mathrm{OH})$.

\subsection{Nanofiber Characterization}

Fiber morphology was examined using a scanning electron microscope (SEM, FEIMagellan 400). All SEM samples were sputter coated for $180 \mathrm{~s}$ with gold (Cressington high-resolution ion beam coater model 108). Fiber diameter was determined using Image $J 1.80$ software (National Institutes of Health, Bethesda, MD) by measuring 30 fibers from high-resolution SEM micrographs. 


\section{CHAPTER 4}

\section{RESULTS AND DISCUSSION}

\subsection{CH-HA Coacervate Formation and Characterization}

Turbidity was used as a qualitative measure to determine the effect that ionic strength, charge stichometry and, $\mathrm{pH}$ value had on coacervate formation. ${ }^{78,73,92-95}$

\subsubsection{Effect of $\mathrm{pH}$ Value}

Kayitmazer's paper shows the $\mathrm{pK}_{\mathrm{a}}$ in $500 \mathrm{mM} \mathrm{NaCl}$ was 2.9 for hyaluronic acid and 6.4 for chitosan from titration experiment (Figure 6) ${ }^{78}$ We optimized the results that chitosan and hyaluronic acid are both fully soluble between $\mathrm{pH}$ values of 2.0 and 6.7, and fully charged around $\mathrm{pH}=4.5 .^{78}$ Therefore, we used $\mathrm{pH}=4.5$ for all the turbidity measurements.

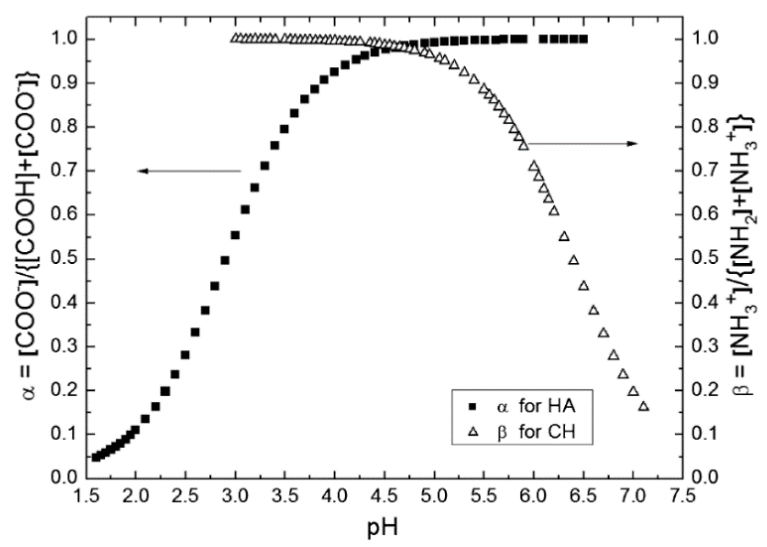

Figure 6. $\mathrm{pH}$ titration profiles for $\mathrm{HA}(234.4 \mathrm{kDa})$ and $\mathrm{CH}(260 \mathrm{kDa}, 83 \% \mathrm{DD})$ in $500 \mathrm{mM}$ $\mathrm{NaCl}^{78}$

\subsubsection{Effect of Charge Stoichiometry}

Maintained a constant $0.001 \mathrm{M}$ total polymer concentration and varied the relative amounts of one polymer to the other with salt present, we observed a max in coacervate formation near 50/50\% chitosan/hyaluronic acid (Figure 7a). This 
observation of maximum coacervate formation at conditions of charge neutrality was expected. ${ }^{73,78}$ Coacervation was not observed at $200 \mathrm{mM} \mathrm{NaCl}$, only precipitates formed, with additional $400 \mathrm{mM} \mathrm{NaCl}$, coacervation was observed in the range from 0.4 to 0.6 (red dashed lines range), whereas precipitates were observed at lower and higher ratios. This broadening of the compositional range for coacervation is thought to be a result of charge screening effects by the additional salt. ${ }^{75}$

\subsubsection{Effect of Salt Concentration}

As evidenced by our stoichiometry experiments, the concentration of salt present can heavily impact coacervation. Figure $\mathbf{7 b}$ shows the range of salt concentrations over which liquid coacervation was observed. At salt concentrations below this range, only solid precipitates were observed; as more salt is present, the larger screening decreases the strength of the electrostatic interaction between polyelectrolytes and enables molecular rearrangement into a liquid coacervate phase; at even higher salt concentrations, the high numbers of ions in solution disfavor the entropic release of counterions, suppressing coacervation and resulting in a single-phase solution. ${ }^{73}$

Since the properties of the solvent are known to have a significant effect on the fiber diameters during electrospinning process, we also studied coacervation in ethanol-water mixtures. With increasing ethanol concentration, we observed a shift in the range of salt concentrations over which coacervation occurred. The minimum salt concentration needed to achieve liquid-liquid phase separation increased from $0.28 \mathrm{M}$ to $0.45 \mathrm{M}$ with the addition of $8 \mathrm{wt} \%$ ethanol. A similar increase in the salt resistance of the system, above which no phase separation was observed, although 
the magnitude of the change was smaller. Thus, we observed a decrease in the overall range of salt concentrations over which coacervation was observed with increasing ethanol. We hypothesize that the addition of ethanol resulted in a decrease in the dielectric constant of the solvent that strengthened the electrostatic interactions driving polyelectrolyte complexation or chitosan and hyaluronic acid can form additional hydrogen bonding.
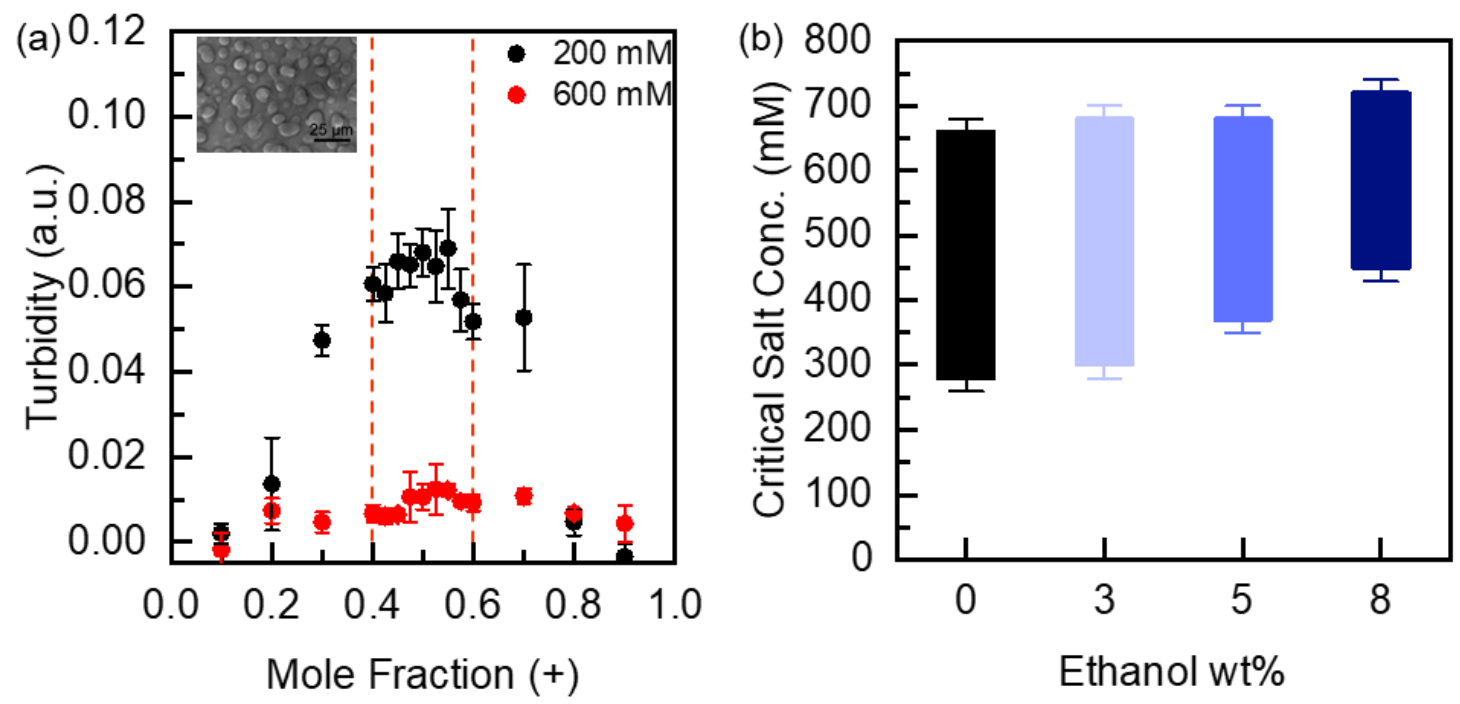

Figure 7. (a) A plot of turbidity as a function of the mole fraction of the chitosan for coacervates of chitosan and hyaluronic acid at different salt concentrations. The red dashes indicated the mole fraction (+) range that form coacervates. (b) A plot of the range of salt concentration over which liquid coacervation was observed at $50 \mathrm{~mol} \%$ chitosan/ hyaluronic acid ratio as a function of ethanol concentration, above this range no complexes were observed and below this range precipitation was formed. All samples were prepared at $1 \mathrm{mM}$ total monomer concentration at $\mathrm{pH} 4.5$.

\subsection{Electrospinning CH-HA Nanofibers}

It has reported that electrospinning can be used to form solid polyelectrolyte complex (PEC) fibers from the synthetic polymer system of PSS and PDADMAC in potassium bromide $(\mathrm{KBr})$ solution. ${ }^{25}$ By using the same traditional single nozzle 
spinneret setup, we were able to successfully electrospin continuous, cylindrical $\mathrm{CH}-\mathrm{HA}$ fibers. For $0 \mathrm{wt} \%$ ethanol samples, the lowest voltage to form continuous fibers was $22 \mathrm{kV}$, resulting in large fibers (average diameter $667 \pm 141 \mathrm{~nm}$ ), which decreased in size with increasing voltage $(162 \pm 37 \mathrm{~nm}$ at $24 \mathrm{Kv}$, Figure 8). This trend is consistent with literature reports that increasing applied voltage results in thinner fibers at a fixed distance from spinneret to collector. ${ }^{13,25,96}$

(a)
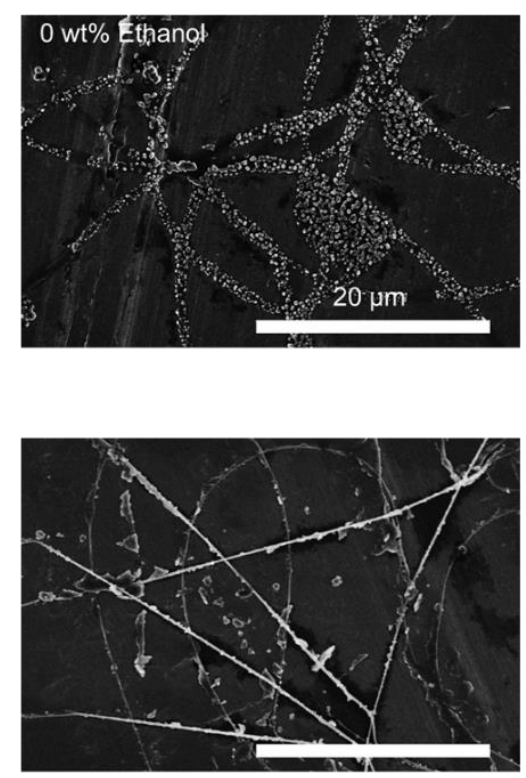
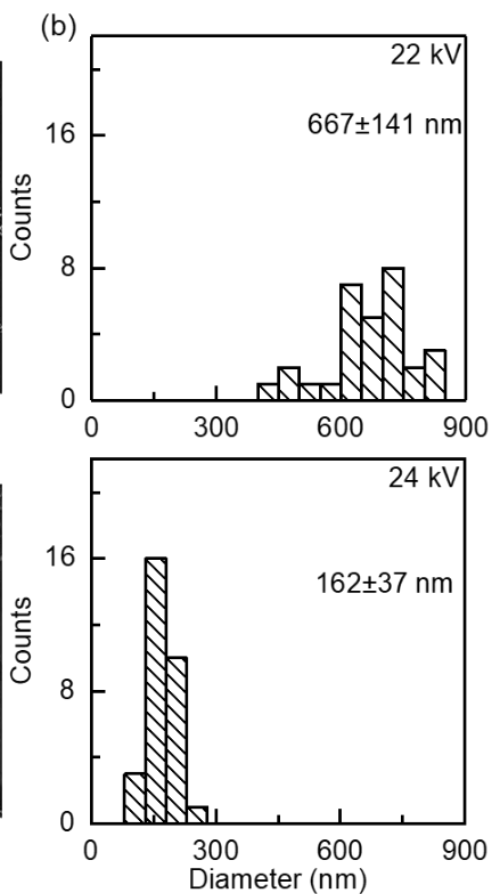

Figure 8. (a) SEM micrographs and (b) plots of the corresponding average fiber diameter as a function of voltage for $0 \mathrm{wt} \%$ ethanol. All fibers were electrospun from $40 \mathrm{mM}$ chitosan-hyaluronic acid, on a monomer basic, in $600 \mathrm{mM} \mathrm{NaCl}$. Electrospinning conditions used were $1 \mathrm{~mL} / \mathrm{hr}, 20 \mathrm{~cm}$ and $24 \%$ humidity.

We further investigated the effects of increasing the concentration of ethanol on the average fiber diameter. During the electrospinning process, the electric field deforms droplets into a Taylor cone, ${ }^{10}$ and a fiber jet is formed and the whips and bends as it moves towards the collector. Ethanol has a low boiling point $\left(78.37^{\circ} \mathrm{C}\right.$ as compared to $100^{\circ} \mathrm{C}$ for water, Table 1), which is beneficial for faster solvent evaporation during fiber whipping 
and bending. This increased rate of evaporation would be expected to facilitate the formation of smaller diameter fibers. While we observed this trend going from $0 \mathrm{wt} \%$ to 3 wt $\%$ ethanol, the average fiber diameter slightly increased with 5 wt $\%$ ethanol (Figure 9b), when increasing the ethanol concentration to $8 \mathrm{wt} \%$, there was no fiber formation. If adding ethanol only made coacervates stiffer (Figure 12), we would expect larger fiber diameters with higher ethanol concertation, but the decreased fiber diameter at $3 \mathrm{wt} \%$ ethanol is more likely due to the faster solvent evaporation.

(a)
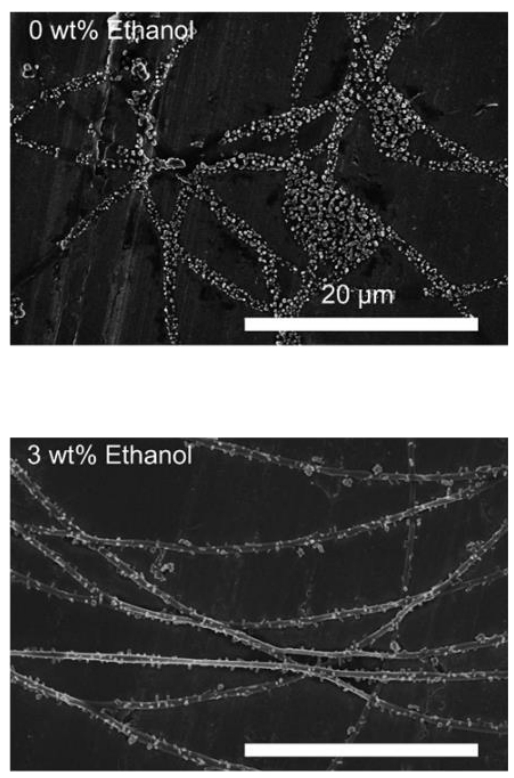

\section{$5 w t \%$ Ethanol}

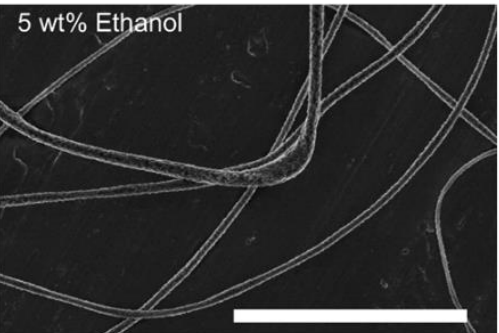

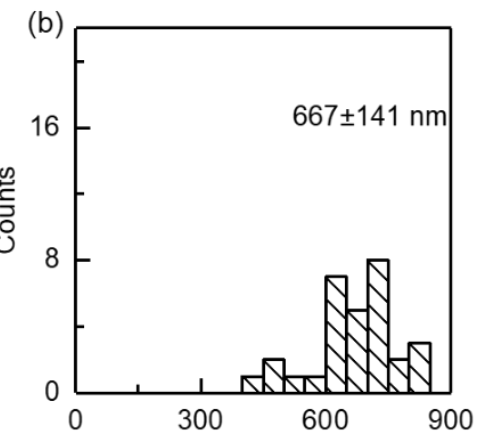
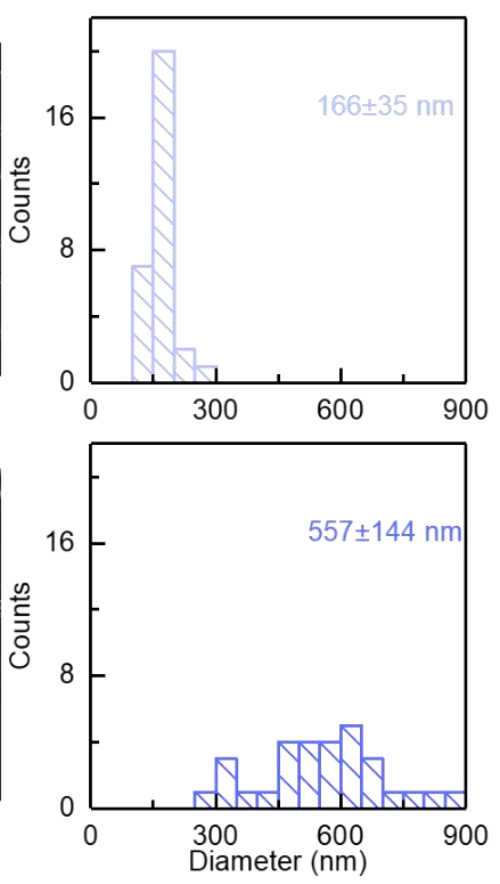

Figure 9. (a) SEM micrographs and (b) plots of the corresponding average fiber diameter for different cosolvent concentrations. All fibers were electrospun from $40 \mathrm{mM}$ chitosan/hyaluronic acid, on a monomer basis, in $600 \mathrm{mM} \mathrm{NaCl}$. Electrospinning conditions used were $1 \mathrm{~mL} / \mathrm{hr}, 22 \mathrm{kV}, 20 \mathrm{~cm}$ and $24 \%$ humidity. 
(a)
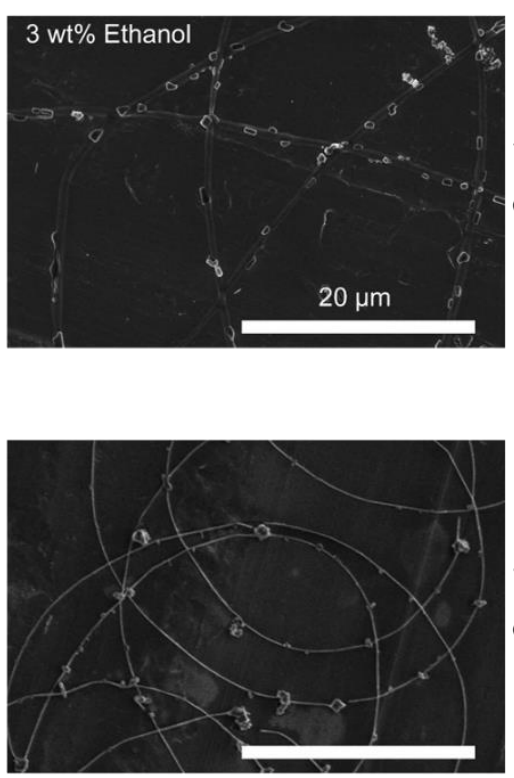

(b)
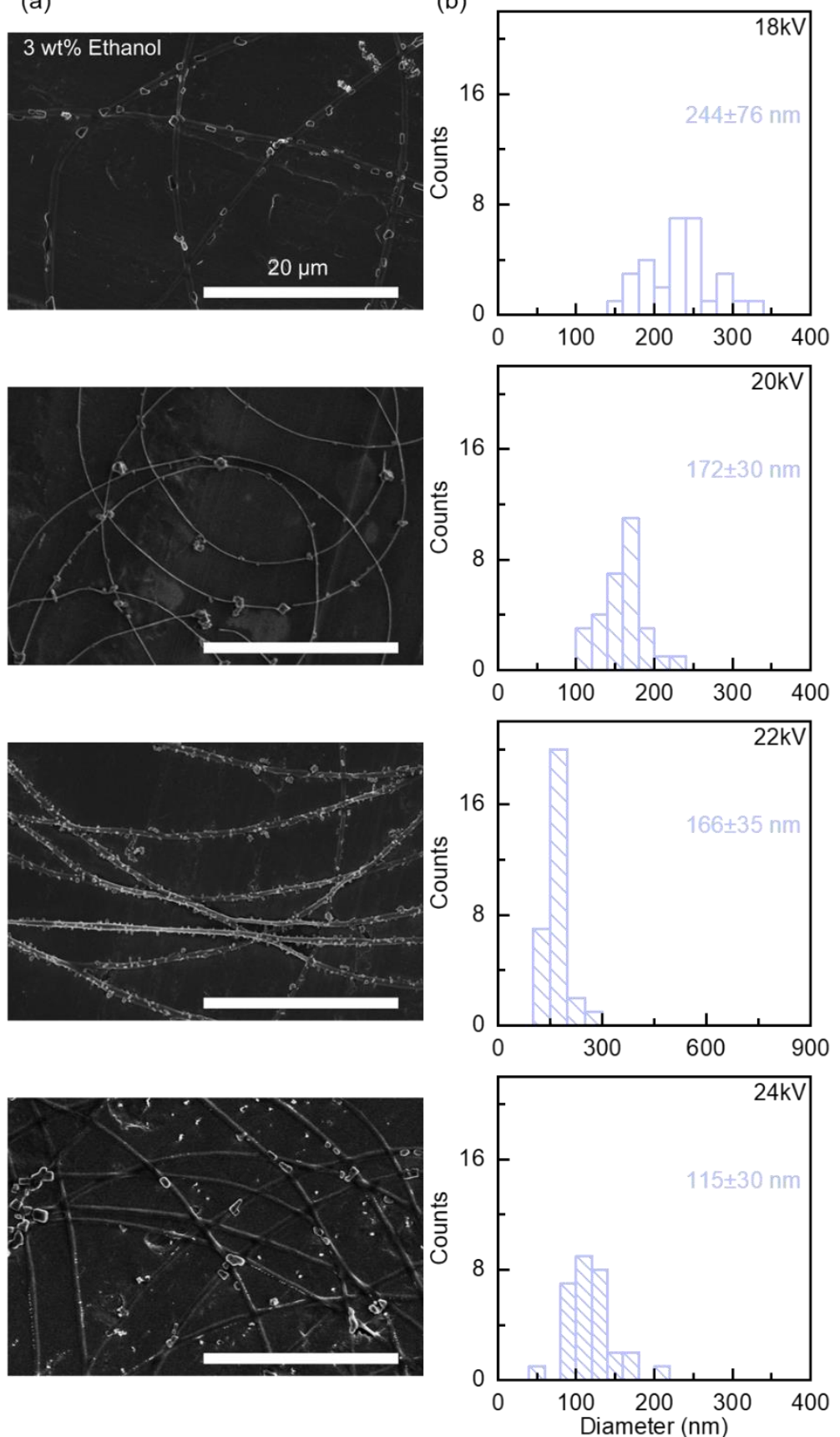

Figure 10. (a) SEM micrographs (b) plots of the corresponding average fiber diameter as a function of voltage for $3 \mathrm{wt} \%$ ethanol. All fibers were electrospun from $40 \mathrm{mM}$ chitosanhyaluronic acid, on a monomer basic, in $600 \mathrm{mM} \mathrm{NaCl}$, respectively. Electrospinning conditions used were $1 \mathrm{~mL} / \mathrm{hr}, 20 \mathrm{~cm}$ and $24 \%$ humidity.

Then we investigated how voltage affected the fiber diameter for 3 wt $\%$ ethanol co-solvent samples (Figure 10). Continuous, cylindrical fibers were 
successfully electrospun from a larger range of operating condition compared to 0 wt $\%$ ethanol samples. PEC fibers started to form at an applied voltage of $18 \mathrm{kV}$ and had an average fiber diameter of $244 \pm 76 \mathrm{~nm}$, while the fibers spun at the higher voltage of $24 \mathrm{kV}$ had the smallest average fiber diameter $(115 \pm 30 \mathrm{~nm})$. Moreover, the trend from our investigation is also consistent with literature reports. ${ }^{13,25,96}$

\subsection{Rheological Characterization of Chitosan-Hyaluronic Acid Coacervates}

The frequency sweep data showed a decrease in the overall magnitude of the storage $\left(\mathrm{G}^{\prime}\right)$ and loss $\left(\mathrm{G}^{\prime \prime}\right)$ moduli with increasing salt concentration (Figure 11a), which indicates salt-induced softening. This trend was observed for all samples, regardless of ethanol composition. For samples at the lowest salt concentration, the linear viscoelastic respond was dominated by the storage modulus over the entire frequency range. However, the loss modulus starts dominating at higher salt concentrations, which demonstrates the more liquid-like materials. Relatedly, we observed a shift in the crossover point to higher frequencies, which is suggestive of salt-induced decrease in the friction between polymer molecules, resulting in a shorter time for disentanglement and relaxation. ${ }^{97,98}$

Table 1. The characterization of different solvents.

\begin{tabular}{|c|c|c|c|c|}
\hline Solvent & $\begin{array}{c}\text { Melting point } \\
\left({ }^{\circ} \mathrm{C}\right)\end{array}$ & $\begin{array}{c}\text { Boiling point } \\
\left({ }^{\circ} \mathrm{C}\right)\end{array}$ & $\begin{array}{c}\text { Dipole Moment } \\
(\text { Debye })\end{array}$ & $\begin{array}{c}\text { Dielectric } \\
\text { Constant }\end{array}$ \\
\hline Water & 0 & 100 & 1.85 & 80.1 \\
\hline Methanol & -97.6 & 64.7 & 1.70 & 32.7 \\
\hline Ethanol & -114.1 & 78.4 & 1.66 & 24.5 \\
\hline
\end{tabular}

We can also compare samples at the same salt concentration but with different amounts of ethanol. We observed an increasing in the magnitude of $G^{\prime}$ and $G^{\prime \prime}$ with 
increasing ethanol weight percent, which indicates stiffening of the samples. We hypothesize that chitosan and hyaluronic acid formed additional hydrogen bonding force with ethanol to make the materials more solid-like ${ }^{93}$ or the additional ethanol resulted in a decrease in the dielectric constant of the solvent as explained before.
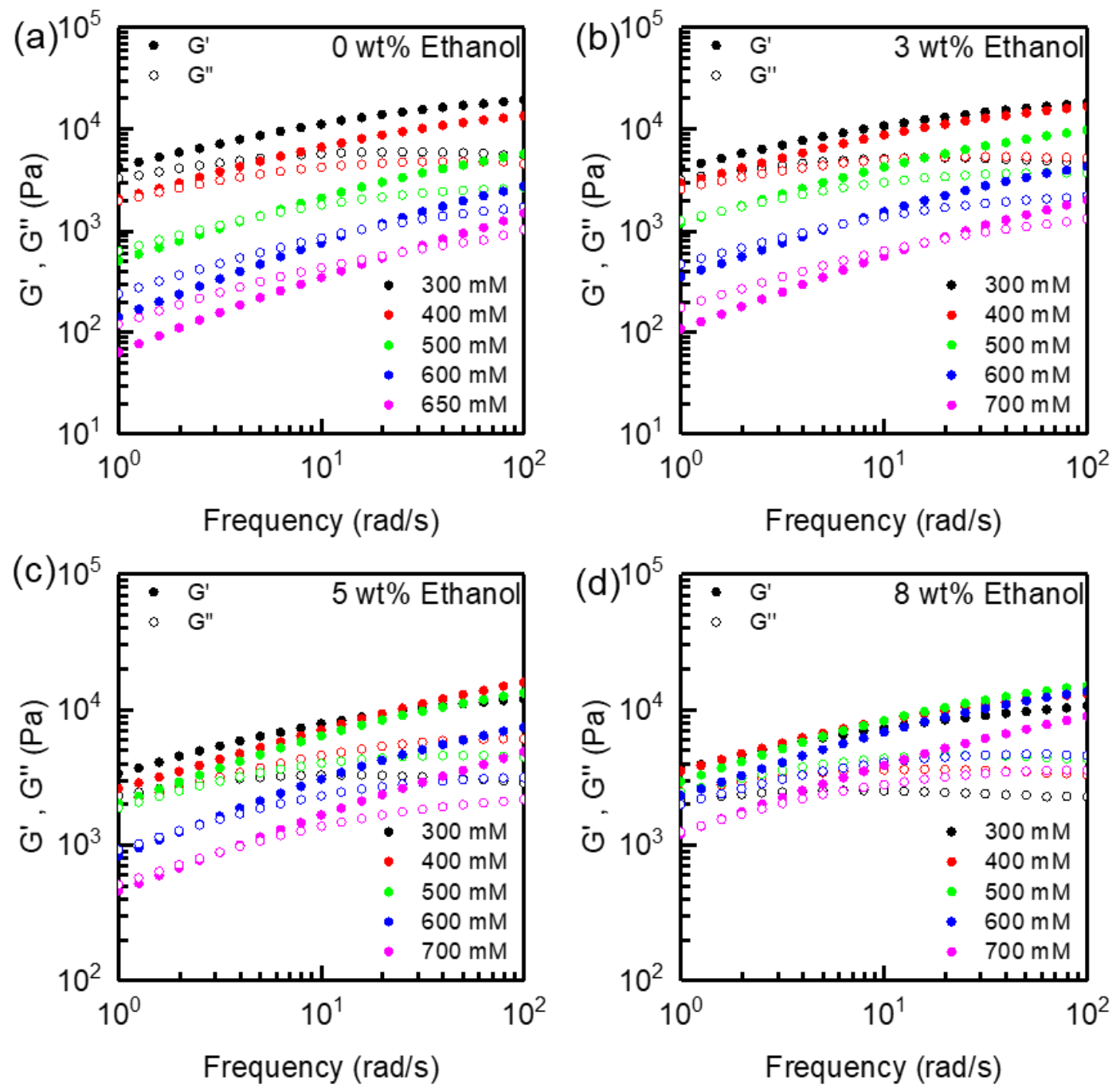

Figure 11. Frequency sweep data for ethanol samples prepared at $300 \mathrm{mM}$ (black), 400 $\mathrm{mM}$ (red), $500 \mathrm{mM}$ (green), $600 \mathrm{mM}$ (blue) and 650/700 $\mathrm{mM}$ (purple) $\mathrm{NaCl}$. Shown as the storage $\left(\mathrm{G}^{\prime}\right)$ moduli (filled circle) and loss $\left(\mathrm{G}^{\prime \prime}\right)$ moduli (open circle). 
Our goal in exploring the rheological properties of the $\mathrm{CH}-\mathrm{HA}$ coacervates was to understand electrospinnability of these materials. Zero-shear viscosity plots are shown in Figure 12a. We observed that increasing the ethanol weight percent increased the viscosity of the coacervate,$^{80}$ while increasing the salt concentration decreased the viscosity. Viscosity could be one of the predictors of spinnability; $8 \mathrm{wt} \%$ ethanol coacervates were too viscous to form fibers. We also examined the relaxation spectrum as a function of salt and ethanol content (Figure 12b). The trend in relaxation behaviour matches with the phase behaviour characterization from turbidity that showed that increasing ethanol resulted in stiffer coacervates.
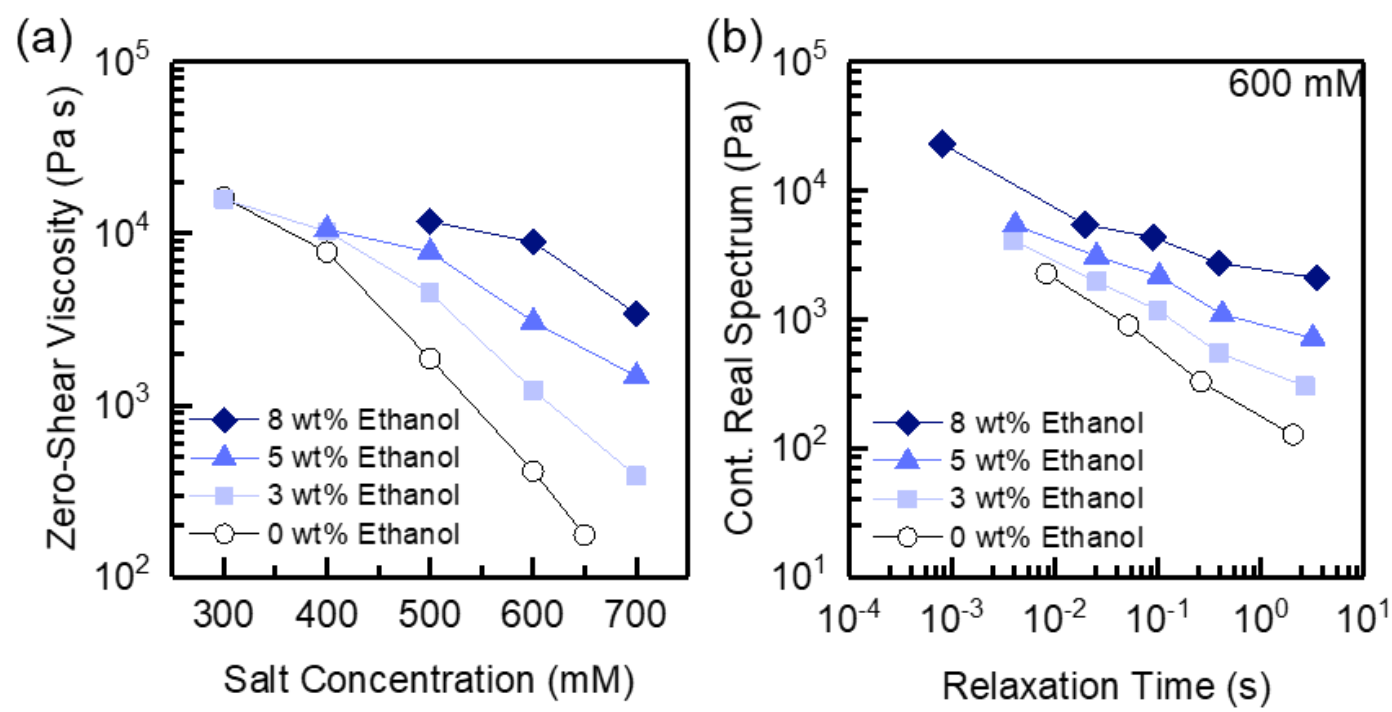

Figure 12. Plots of (a) zero-shear viscosity of $\mathrm{CH}-\mathrm{HA}$ coacervates as a function of salt and ethanol content, and (b) the corresponding relaxation spectra for coacervates prepared at $600 \mathrm{mM} \mathrm{NaCl}$ over a range of ethanol concentrations. 


\section{CHAPTER 5}

\section{CONCLUSION}

In summary, we successfully electrospun PEC fibers from CH-HA coacervates in pure water and ethanol-water co-solvent mixtures. We have demonstrated that the addition of ethanol helps solvent evaporation during electrospinning process, as well as facilitating electrospinning across a broader range of electrospinning apparatus parameters. Furthermore, ethanol is a relatively biocompatible solvent, which would make these nanofibers excellent candidates for use in medical applications. 


\section{CHAPTER 6}

\section{FUTURE WORK}

Although this work has successfully electrospun nanofibers from $\mathrm{CH}-\mathrm{HA}$ coacervates, the further biomedical application could follow from this project. As-spun nanofibers mats can be modified with functional agents (e.g., drugs, polymers). For example, lysostaphin was immobilized onto biocompatible fibers to obtain bandage that showed bactericidal activity against $\mathrm{S}$. aureus displayed low toxicity towards keratinocytes which showed these materials could be used in wound healing applications. ${ }^{99}$ 
APPENDIX: RHEOLOGICAL CHARACTERIZATION OF CHITOSAN-

HYALURONIC ACID COACERVATES
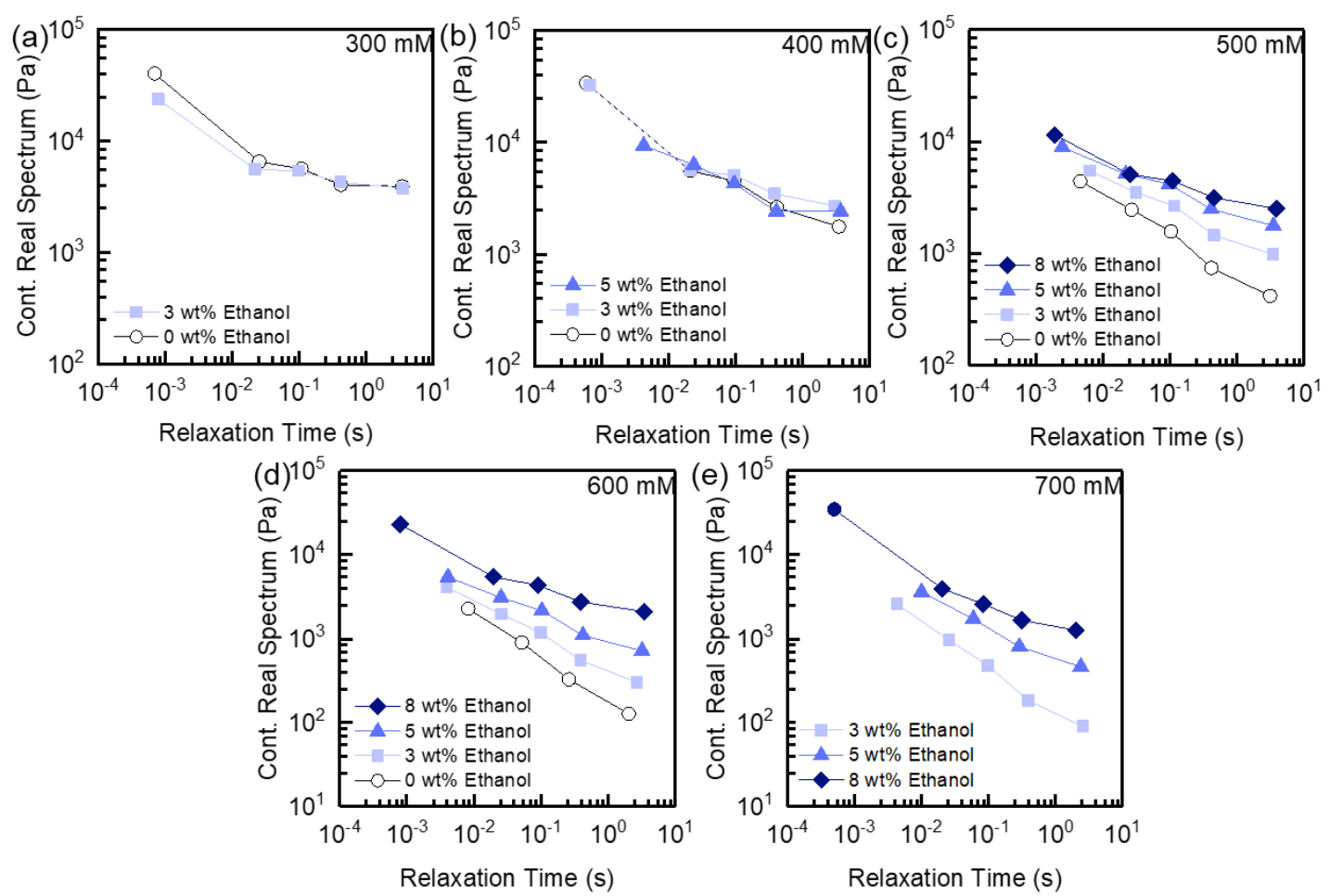

Figure 13. Plots of relaxation spectra for CH-HA coacervates prepared at $300 \mathrm{mM}, 400$ $\mathrm{mM} 500 \mathrm{mM} 600 \mathrm{mM} 700 \mathrm{mM} \mathrm{NaCl}$ over a range of ethanol concentrations. 

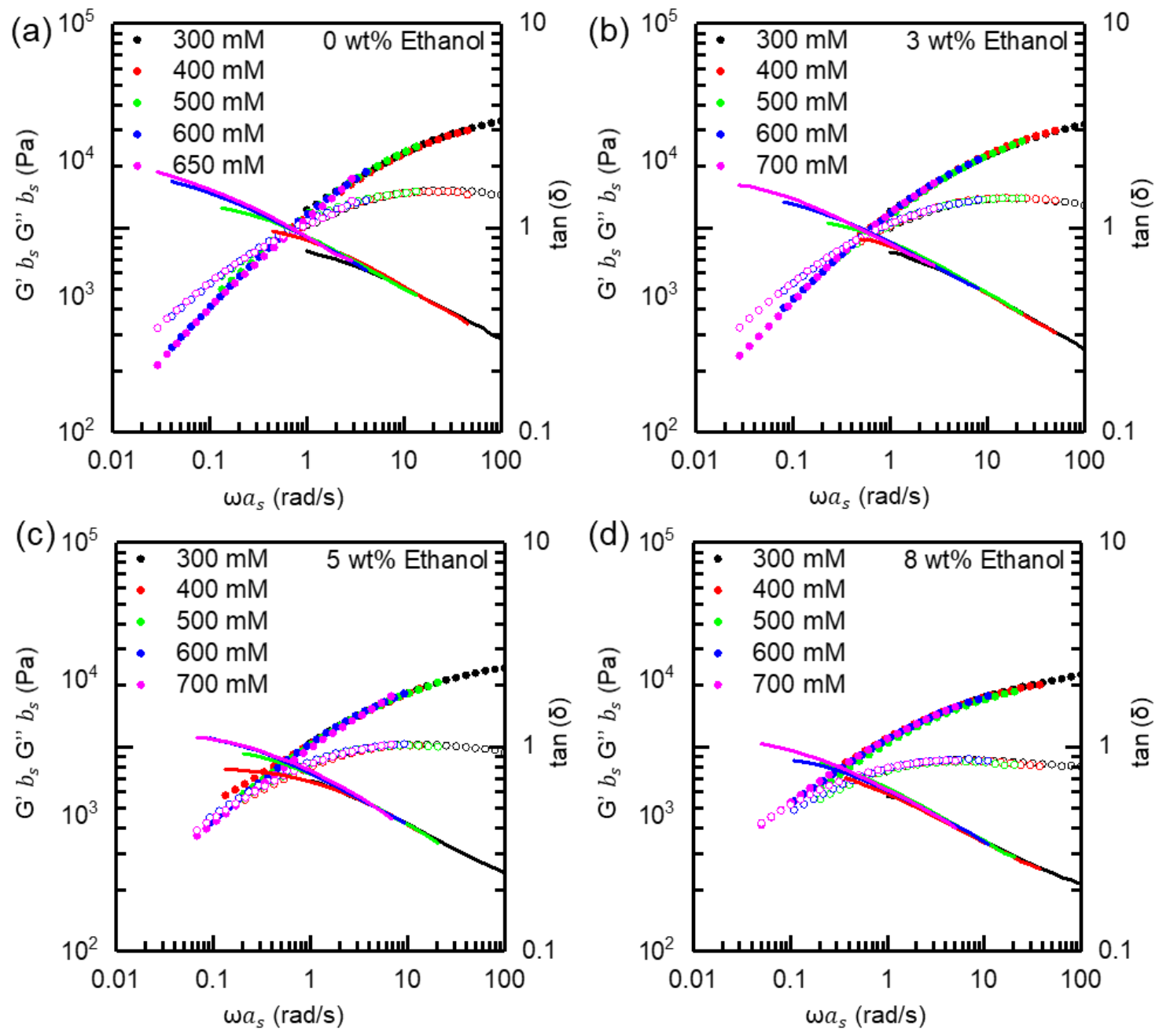

Figure 14. Plots of the time-salt superposition of frequency sweep data for CH-HA complex coacervates ( $300 \mathrm{mM}$ to $700 \mathrm{mM} \mathrm{NaCl}$ ), shifted with respect to the $300 \mathrm{mM}$ " as prepared" data. $300 \mathrm{mM}$ (black), $400 \mathrm{mM}$ (red), $500 \mathrm{mM}$ (green), $600 \mathrm{mM}$ (blue), and 650/700 mM (purple) $\mathrm{NaCl}$. 

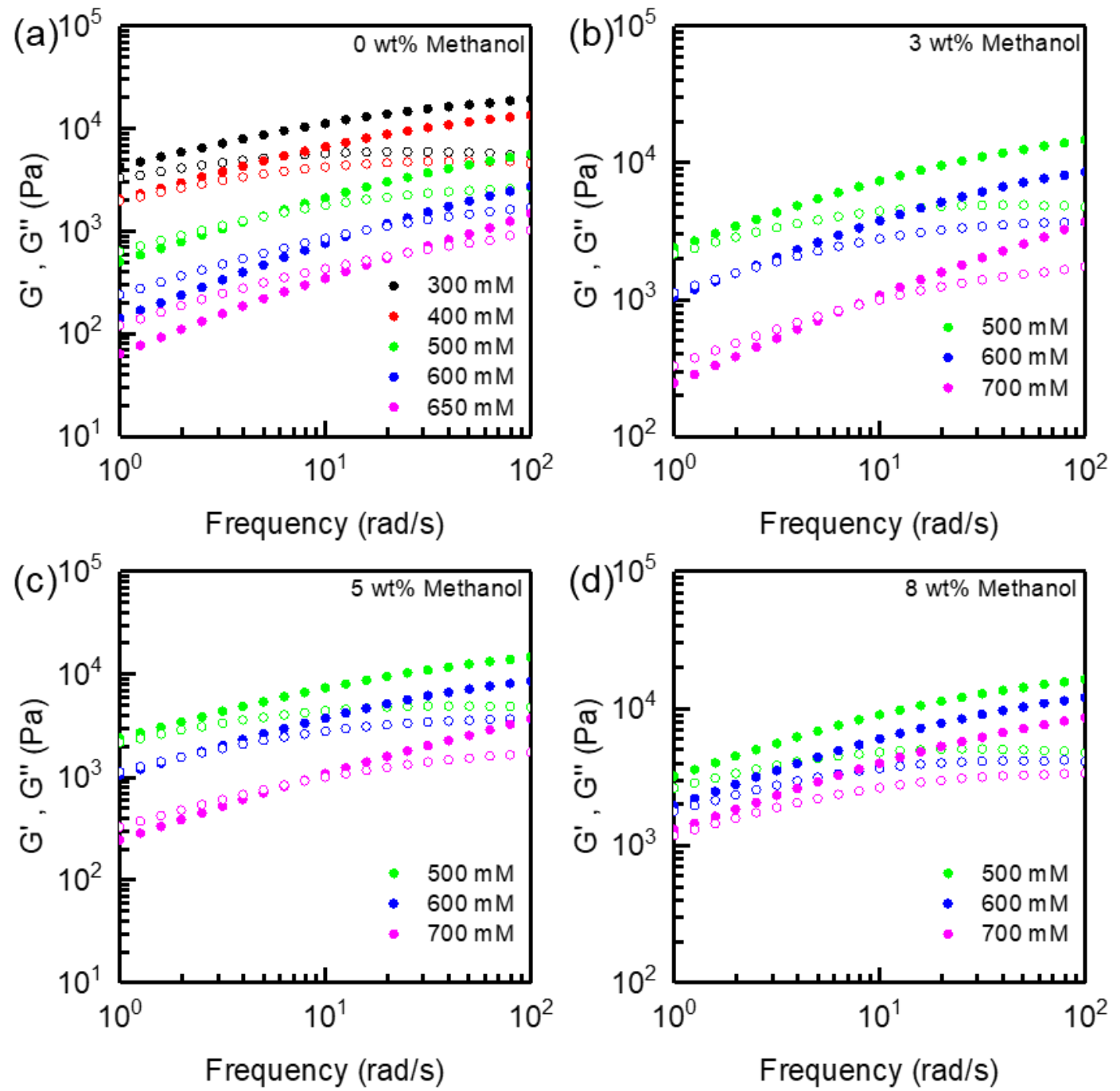

Figure 15. Frequency sweep data for $\mathrm{CH}-\mathrm{HA}$ methanol cosolvent. Coacervates prepared using $500 \mathrm{mM}$ (green), $600 \mathrm{mM}$ (blue) and 650/700 $\mathrm{mM}$ (purple) $\mathrm{NaCl}$. Shown as the storage $\left(\mathrm{G}^{\prime}\right)$ moduli (filled circle) and loss $\left(\mathrm{G}^{\prime \prime}\right)$ moduli (open circle). 

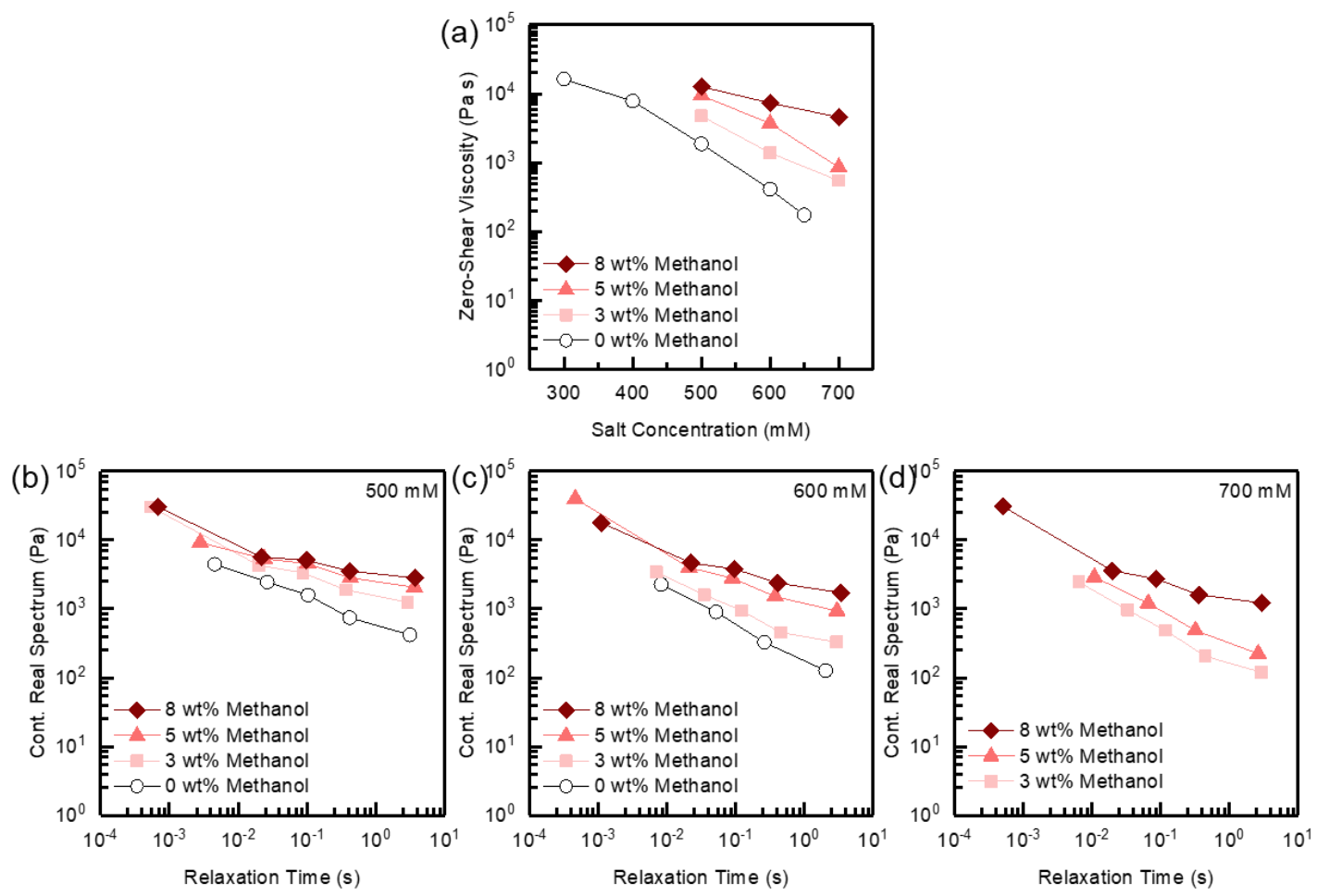

Figure 16. Plots of (a) zero-shear viscosity of $\mathrm{CH}-\mathrm{HA}$ coacervates as a function of salt and methanol content, and (b) (c) (d) the corresponding relaxation spectra for coacervates prepared at $500 \mathrm{Mm} 600 \mathrm{mM} 700 \mathrm{mM} \mathrm{NaCl}$ over a range of methanol concentrations. 


\section{REFERENCES}

(1) Wan, A. C. A.; Cutiongco, M. F. A.; Tai, B. C. U.; Leong, M. F.; Lu, H. F.; Yim, E. K. F. Fibers by Interfacial Polyelectrolyte Complexation - Processes, Materials and Applications. Biochem. Pharmacol. 2016, 19 (8), 437-450. https://doi.org/10.1016/j.mattod.2016.01.017.

(2) Ramakrishna, S.; Fujihara, K.; Teo, W. E.; Yong, T.; Ma, Z.; Ramaseshan, R. Electrospun Nanofibers: Solving Global Issues. Mater. Today 2006, 9 (3), 40-50. https://doi.org/10.1016/S1369-7021(06)71389-X.

(3) Rieger, K. A.; Birch, N. P.; Schiffman, J. D. Designing Electrospun Nanofiber Mats to Promote Wound Healing-a Review. J. Mater. Chem. B 2013, 1 (36), 4531-4541. https://doi.org/10.1039/c3tb20795a.

(4) Liang, D.; Hsiao, B. S.; Chu, B. Functional Electrospun Nanofibrous Scaffolds for Biomedical Applications. Adv. Drug Deliv. Rev. 2007, 59 (14), 1392-1412. https://doi.org/10.1016/j.addr.2007.04.021.

(5) Cui, W.; Zhou, Y.; Chang, J. Electrospun Nanofibrous Materials for Tissue Engineering and Drug Delivery. Sci. Technol. Adv. Mater. 2010, 11 (1), 014108. https://doi.org/10.1088/1468-6996/11/1/014108.

(6) Meng, J.; Han, Z.; Kong, H.; Qi, X.; Wang, C.; Xie, S.; Xu, H. Electrospun Aligned Nanofibrous Composite of MWCNT/Polyurethane to Enhance Vascular Endothelium Cells Proliferation and Function. J. Biomed. Mater. Res. - Part A 2010, 95 (1), 312-320. https://doi.org/10.1002/jbm.a.32845.

(7) Ignatova, M.; Manolova, N.; Rashkov, I. Electrospun Antibacterial Chitosan-Based Fibers. Macromol. Biosci. 2013, 13 (7), 860-872. https://doi.org/10.1002/mabi.201300058.

(8) Son, Y. J.; Kim, W. J.; Yoo, H. S. Therapeutic Applications of Electrospun Nanofibers for Drug Delivery Systems. Arch. Pharm. Res. 2014, 37 (1), 69-78. https://doi.org/10.1007/s12272-013-0284-2.

(9) Engel, Y.; Schiffman, J. D.; Goddard, J. M.; Rotello, V. M. Nanomanufacturing of Biomaterials. Mater. Today 2012, 15 (11), 478-485. https://doi.org/10.1016/S13697021(12)70217-1.

(10) Latham, J.; Roxburgh, I. W. Disintegration of Pairs of Water Drops in an Electric Field. Proc. R. Soc. A Math. Phys. Eng. Sci. 1966, 295 (1440), 84-97. https://doi.org/10.1098/rspa.1966.0227.

(11) Montinaro, M.; Fasano, V.; Moffa, M.; Camposeo, A.; Persano, L.; Lauricella, M.; Succi, S.; Pisignano, D. Sub-Ms Dynamics of the Instability Onset of Electrospinning. Soft Matter 2015, 11 (17), 3424-3431. https://doi.org/10.1039/c4sm02708f. 
(12) Reneker, D. H.; Yarin, A. L.; Fong, H.; Koombhongse, S. Bending Instability of Electrically Charged Liquid Jets of Polymer Solutions in Electrospinning Bending Instability of Electrically Charged Liquid Jets of Polymer Solutions in Electrospinning. 2004, 4531 (2000). https://doi.org/10.1063/1.373532.

(13) Thompson, C. J.; Chase, G. G.; Yarin, A. L.; Reneker, D. H. Effects of Parameters on Nanofiber Diameter Determined from Electrospinning Model. Polymer (Guildf). 2007, 48 (23), 6913-6922. https://doi.org/10.1016/j.polymer.2007.09.017.

(14) Zong, X.; Kim, K.; Fang, D.; Ran, S.; Hsiao, B. S.; Chu, B. Structure and Process Relationship of Electrospun Bioabsorbable Nanofiber Membranes. 2002, 43, 44034412.

(15) Regev, O.; Vandebril, S.; Zussman, E.; Clasen, C. The Role of Interfacial Viscoelasticity in the Stabilization of an Electrospun Jet. Polymer (Guildf). 2010, 51 (12), 2611-2620. https://doi.org/10.1016/j.polymer.2010.03.061.

(16) Colby, R. H. Structure and Linear Viscoelasticity of Flexible Polymer Solutions: Comparison of Polyelectrolyte and Neutral Polymer Solutions. Rheol. Acta 2010, 49 (5), 425-442. https://doi.org/10.1007/s00397-009-0413-5.

(17) Klossner, R. R.; Queen, H. a; Coughlin, A. J.; Krause, W. E. Correlation of Chitosan 's Rheological Properties and Its Ability to Electrospin. Biomacromolecules 2008, 9, 2947-2953. https://doi.org/10.1021/bm800738u.

(18) Shenoy, S. L.; Bates, W. D.; Frisch, H. L.; Wnek, G. E. Role of Chain Entanglements on Fiber Formation during Electrospinning of Polymer Solutions: Good Solvent, Non-Specific Polymer-Polymer Interaction Limit. Polymer (Guildf). 2005, 46 (10), 3372-3384. https://doi.org/10.1016/j.polymer.2005.03.011.

(19) Mckee, M. G.; Wilkes, G. L.; Colby, R. H.; Long, T. E. Correlations of Solution Rheology with Electrospun Fiber Formation of Linear and Branched Polyesters. 2004, 1760-1767.

(20) Boland, E. D.; Telemeco, T. A.; Simpson, D. G.; Wnek, G. E.; Bowlin, G. L. Utilizing Acid Pretreatment and Electrospinning to Improve Biocompatibility of Poly ( Glycolic Acid ) for Tissue Engineering. 2004, 144-152. https://doi.org/10.1002/jbm.b.30105.

(21) Verreck, G.; Chun, I.; Rosenblatt, J.; Peeters, J.; Dijck, A. Van; Mensch, J.; Noppe, M.; Brewster, M. E. Incorporation of Drugs in an Amorphous State into Electrospun Nanofibers Composed of a Water-Insoluble, Nonbiodegradable Polymer. 2003, 92, 349-360. https://doi.org/10.1016/S0168-3659(03)00342-0.

(22) Yao, L.; Haas, T. W.; Guiseppi-elie, A.; Bowlin, G. L.; Simpson, D. G.; Wnek, G. E. Electrospinning and Stabilization of Fully Hydrolyzed Poly ( Vinyl Alcohol ) Fibers. 2003, 000, 1860-1864.

(23) Ding, B. I. N.; Kim, H.; Lee, S.; Shao, C.; Lee, D.; Park, S.; Kwag, G.; Choi, K. 
Preparation and Characterization of a Nanoscale Poly ( Vinyl Alcohol ) Fiber Aggregate Produced by an Electrospinning Method. 2002, 1261-1268. https://doi.org/10.1002/polb.10191.

(24) Keun, W.; Ho, J.; Seung, T.; Ho, W. The Effects of Solution Properties and Polyelectrolyte on Electrospinning of Ultrafine Poly ( Ethylene Oxide ) Fibers. 2004, 45, 2959-2966. https://doi.org/10.1016/j.polymer.2004.03.006.

(25) Meng, X.; Perry, S. L.; Schiffman, J. D. Complex Coacervation: Chemically Stable Fibers Electrospun from Aqueous Polyelectrolyte Solutions. ACS Macro Lett. 2017, 6 (5), 505-511. https://doi.org/10.1021/acsmacrolett.7b00173.

(26) Jeong, S. I.; Krebs, M. D.; Bonino, C. A.; Khan, S. A.; Alsberg, E. Electrospun Alginate Nanofibers with Controlled Cell Adhesion for Tissue Engineering. Macromol. Biosci. 2010, 10 (8), 934-943. https://doi.org/10.1002/mabi.201000046.

(27) Hussain, T.; Masood, R.; Umar, M.; Areeb, T.; Ullah, A. Development and Characterization of Alginate-Chitosan-Hyaluronic Acid (ACH) Composite Fibers for Medical Applications. Fibers Polym. 2016, 17 (11), 1749-1756. https://doi.org/10.1007/s12221-016-6487-7.

(28) Liu, H.; Hsieh, Y. Lo. Ultrafine Fibrous Cellulose Membranes from Electrospinning of Cellulose Acetate. J. Polym. Sci. Part B Polym. Phys. 2002, 40 (18), 2119-2129. https://doi.org/10.1002/polb.10261.

(29) Huang, Z. M.; Zhang, Y. Z.; Ramakrishna, S.; Lim, C. T. Electrospinning and Mechanical Characterization of Gelatin Nanofibers. Polymer (Guildf). 2004, 45 (15), 5361-5368. https://doi.org/10.1016/j.polymer.2004.04.005.

(30) Maeda, N.; Miao, J.; Simmons, T. J.; Dordick, J. S.; Linhardt, R. J. Composite Polysaccharide Fibers Prepared by Electrospinning and Coating. Carbohydr. Polym. 2014, 102 (1), 950-955. https://doi.org/10.1016/j.carbpol.2013.10.038.

(31) Cho, D.; Nnadi, O.; Netravali, A.; Joo, Y. L. Electrospun Hybrid Soy Protein/PVA Fibers. Macromol. Mater. Eng. 2010, 295 (8), 763-773. https://doi.org/10.1002/mame.201000161.

(32) Barnes, C.; Smith, M.; Bowlin, G.; Sell, S. Feasibility of Electrospinning the Globular Proteins Hemoglobin and Myoglobin. J. Eng. Fiber. Fabr. 2006, 1 (2), 1629.

(33) Pakravan, M.; Heuzey, M. C.; Ajji, A. Core-Shell Structured PEO-Chitosan Nanofibers by Coaxial Electrospinning. Biomacromolecules 2012, 13 (2), 412-421. https://doi.org/10.1021/bm201444v.

(34) Ohkawa, K.; Cha, D.; Kim, H.; Nishida, A.; Yamamoto, H. Electrospinning of Chitosan. Macromol. Rapid Commun. 2004, 25 (18), 1600-1605. https://doi.org/10.1002/marc.200400253.

(35) Brenner, E. K.; Schiffman, J. D.; Thompson, E. A.; Toth, L. J.; Schauer, C. L. 
Electrospinning of Hyaluronic Acid Nanofibers from Aqueous Ammonium Solutions. Carbohydr. Polym. 2012, 87 (1), $926-929$. https://doi.org/10.1016/j.carbpol.2011.07.033.

(36) Uppal, R.; Ramaswamy, G. N.; Arnold, C.; Goodband, R.; Wang, Y. Hyaluronic Acid Nanofiber Wound Dressing - Production, Characterization, and in Vivo Behavior. 2011. https://doi.org/10.1002/jbm.b.31776.

(37) Vecchies, F.; Sacco, P.; Decleva, E.; Menegazzi, R.; Porrelli, D.; Donati, I.; Turco, G.; Paoletti, S.; Marsich, E. Complex Coacervates between a Lactose-Modified Chitosan and Hyaluronic Acid as Radical-Scavenging Drug Carriers. Biomacromolecules 2018, 19, 3936-3944. https://doi.org/10.1021/acs.biomac.8b00863.

(38) Lallana, E.; Rios De La Rosa, J. M.; Tirella, A.; Pelliccia, M.; Gennari, A.; Stratford, I. J.; Puri, S.; Ashford, M.; Tirelli, N. Chitosan/Hyaluronic Acid Nanoparticles: Rational Design Revisited for RNA Delivery. Mol. Pharm. 2017, 14 (7), 24222436. https://doi.org/10.1021/acs.molpharmaceut.7b00320.

(39) Sangsanoh, P.; Suwantong, O.; Neamnark, A.; Cheepsunthorn, P.; Pavasant, P.; Supaphol, P. In Vitro Biocompatibility of Electrospun and Solvent-Cast Chitosan Substrata towards Schwann, Osteoblast, Keratinocyte and Fibroblast Cells. Eur. Polym. J. 2010, 46 (3), 428-440. https://doi.org/10.1016/j.eurpolymj.2009.10.029.

(40) Huang, X.; Ge, D.; Xu, Z. POLYMER Preparation and Characterization of Stable Chitosan Nanofibrous Membrane for Lipase Immobilization. 2007, 43, 3710-3718. https://doi.org/10.1016/j.eurpolymj.2007.06.010.

(41) Desai, K.; Kit, K.; Li, J.; Michael Davidson, P.; Zivanovic, S.; Meyer, H. Nanofibrous Chitosan Non-Wovens for Filtration Applications. Polymer (Guildf). 2009, 50 (15), 3661-3669. https://doi.org/10.1016/j.polymer.2009.05.058.

(42) Zhang, Y.; Huang, X.; Duan, B. Preparation of Electrospun Chitosan / Poly ( Vinyl Alcohol ) Membranes. 2007, 855-863. https://doi.org/10.1007/s00396-006-1630-4.

(43) Ignatova, M. G.; Manolova, N. E.; Toshkova, R. A.; Rashkov, I. B.; Gardeva, E. G.; Yossifova, L. S.; Alexandrov, M. T. Electrospun Nanofibrous Mats Containing Quaternized Chitosan and Polylactide with In Vitro Antitumor Activity against HeLa Cells. 2010, 1633-1645.

(44) Haider, S.; Park, S. Preparation of the Electrospun Chitosan Nanofibers and Their Applications to the Adsorption of $\mathrm{Cu}$ ( II ) and $\mathrm{Pb}$ ( II ) Ions from an Aqueous Solution. 2009, 328, 90-96. https://doi.org/10.1016/j.memsci.2008.11.046.

(45) Kim, T. G.; Chung, H. J.; Park, T. G. Macroporous and Nanofibrous Hyaluronic Acid / Collagen Hybrid Scaffold Fabricated by Concurrent Electrospinning and Deposition / Leaching of Salt Particles. 2008, 4, 1611-1619. https://doi.org/10.1016/j.actbio.2008.06.008. 
(46) Jia, X.; Kiick, K. L. Hybrid Multicomponent Hydrogels for Tissue Engineering. 2009, 140-156. https://doi.org/10.1002/mabi.200800284.

(47) Jung, K.; Huh, M.; Meng, W.; Yuan, J.; Hyun, S. H.; Bae, J.; Hudson, S. M.; Kang, I. Preparation and Antibacterial Activity of PET / Chitosan Nanofibrous Mats Using an Electrospinning Technique. 2006. https://doi.org/10.1002/app.

(48) Yoo, H. S.; Lee, E. A.; Yoon, J. J.; Park, T. G. Hyaluronic Acid Modified Biodegradable Scaffolds for Cartilage Tissue Engineering. 2005, 26, 1925-1933. https://doi.org/10.1016/j.biomaterials.2004.06.021.

(49) Desai, K.; Kit, K.; Li, J.; Zivanovic, S. Morphological and Surface Properties of Electrospun Chitosan Nanofibers. Biomacromolecules 2008, 9 (3), 1000-1006. https://doi.org/10.1021/bm701017z.

(50) Zhang, R. Y.; Zaslavski, E.; Vasilyev, G.; Boas, M.; Zussman, E. Tunable PHResponsive Chitosan-Poly(Acrylic Acid) Electrospun Fibers. Biomacromolecules 2018, 19 (2), 588-595. https://doi.org/10.1021/acs.biomac.7b01672.

(51) de Farias, B. S.; Sant'Anna Cadaval Junior, T. R.; de Almeida Pinto, L. A. ChitosanFunctionalized Nanofibers: A Comprehensive Review on Challenges and Prospects for Food Applications. Int. J. Biol. Macromol. 2018, \#pagerange\#. https://doi.org/10.1016/j.ijbiomac.2018.11.042.

(52) Shi, R.; Sun, T. L.; Luo, F.; Nakajima, T.; Kurokawa, T.; Bin, Y. Z.; Rubinstein, M.; Gong, J. P. [ASAP] Elastic-Plastic Transformation of Polyelectrolyte Complex Hydrogels from Chitosan and Sodium Hyaluronate. Macromolecules 2018, 51, 8887-8898. https://doi.org/10.1021/acs.macromol.8b01658.

(53) Lalevée, G.; Sudre, G.; Montembault, A.; Meadows, J.; Malaise, S.; Crépet, A.; David, L.; Delair, T. Polyelectrolyte Complexes via Desalting Mixtures of Hyaluronic Acid and Chitosan-Physicochemical Study and Structural Analysis. Carbohydr. Polym. 2016, 154, 86-95. https://doi.org/10.1016/j.carbpol.2016.08.007.

(54) Um, I. C.; Fang, D.; Hsiao, B. S.; Okamoto, A.; Chu, B. Electro-Spinning and Electro-Blowing of Hyaluronic Acid. Biomacromolecules 2004, 5 (4), 1428-1436. https://doi.org/10.1021/bm034539b.

(55) Mondek, J.; Kalina, M.; Simulescu, V.; Pekař, M. Thermal Degradation of High Molar Mass Hyaluronan in Solution and in Powder; Comparison with BSA. Polym. Degrad. Stab. 2015, 120, 107-113. https://doi.org/10.1016/j.polymdegradstab.2015.06.012.

(56) Price, R. D.; Myers, S.; Leigh, I. M.; Navsaria, H. A. The Role of Hyaluronic Acid in Wound Healing Assessment of Clinical Evidence. 2005, 6 (6), 393-402.

(57) Schiffman, J. D.; Schauer, C. L. A Review: Electrospinning of Biopolymer Nanofibers and Their A Review : Electrospinning of Biopolymer Nanofibers and 
Their Applications. 2008, No. August 2014. https://doi.org/10.1080/15583720802022182.

(58) Mckee, M. G.; Elkins, C. L.; Long, T. E. Influence of Self-Complementary Hydrogen Bonding on Solution Rfile:///C:/Users/Sun Sun/Desktop/Thesis/References/43. Electrospinning of Chitosan Dissolved in Concentrated Acetic Acid Solution.Pdfheology / Electrospinning Relationships. 2004, $c$, 8705-8715. https://doi.org/10.1016/j.polymer.2004.10.049.

(59) Sun, K.; Li, Z. H. Preparations, Properties and Applications of Chitosan Based Nanofibers Fabricated by Electrospinning. Express Polym. Lett. 2011, 5 (4), 342361. https://doi.org/10.3144/expresspolymlett.2011.34.

(60) Schiffman, J. D.; Schauer, C. L. One-Step Electrospinning of Cross-Linked Chitosan Fibers. 2007, 2665-2667.

(61) Schiffman, J. D.; Schauer, C. L. Cross-Linking Chitosan Nanofibers. 2007, 594601.

(62) Hasegawa, M. A. K. O. T. O.; Isogai, A.; Usuda, M. A. K. O. T. O. Dissolving States of Cellulose and Chitosan in Trifluoroacetic Acid. 1857, 1857-1863.

(63) Chen, Z.; Mo, X.; Qing, F. Electrospinning of Collagen - Chitosan Complex. 2007, 61, 3490-3494. https://doi.org/10.1016/j.matlet.2006.11.104.

(64) Chen, Z.; He, C.; Wang, H. Intermolecular Interactions in Electrospun Collagen Chitosan Complex Nanofibers. 2008, 72, 410-418. https://doi.org/10.1016/j.carbpol.2007.09.018.

(65) Kriegel, C.; Kit, K. M.; Mcclements, D. J.; Weiss, J. Electrospinning of Chitosan Poly ( Ethylene Oxide ) Blend Nanofibers in the Presence of Micellar Surfactant Solutions. 2009, 50, 189-200. https://doi.org/10.1016/j.polymer.2008.09.041.

(66) Neamnark, A.; Rujiravanit, R.; Supaphol, P. Electrospinning of Hexanoyl Chitosan. 2006, 66, 298-305. https://doi.org/10.1016/j.carbpol.2006.03.015.

(67) Mincheva, R.; Manolova, N.; Rashkov, I. POLYMER Bicomponent Aligned Nanofibers of N -Carboxyethylchitosan and Poly ( Vinyl Alcohol ). 2007, 43, 28092818. https://doi.org/10.1016/j.eurpolymj.2007.04.020.

(68) Zhou, Y.; Yang, D.; Chen, X.; Xu, Q.; Lu, F. Electrospun Water-Soluble Carboxyethyl Chitosan / Poly ( Vinyl Alcohol ) Nanofibrous Membrane as Potential Wound Dressing for Skin Regeneration. 2008, 349-354.

(69) Brenner, E. K.; Schiffman, J. D.; Schauer, C. L. Phosphate Salts Facilitate the Electrospinning of Hyaluronic Acid Fiber Mats. 2013, 7805-7811. https://doi.org/10.1007/s10853-013-7532-1.

(70) Li, J.; He, A.; Zheng, J.; Han, C. C. Gelatin and Gelatin - Hyaluronic Acid Nanofibrous Membranes Produced by Electrospinning of Their Aqueous Solutions. 
Biomacromolecules 2006, 7 (7), 2243-2247. https://doi.org/10.1021/bm0603342.

(71) Hsu, F. Y.; Hung, Y. S.; Liou, H. M.; Shen, C. H. Electrospun Hyaluronate-Collagen Nanofibrous Matrix and the Effects of Varying the Concentration of Hyaluronate on the Characteristics of Foreskin Fibroblast Cells. Acta Biomater. 2010, 6 (6), 21402147. https://doi.org/10.1016/j.actbio.2009.12.023.

(72) Li, J.; He, A.; Han, C. C.; Fang, D.; Hsiao, B. S.; Chu, B. Electrospinning of Hyaluronic Acid (HA) and HA/ Gelatin Blends. Macromol. Rapid Commun. 2006, 27 (2), 114-120. https://doi.org/10.1002/marc.200500726.

(73) Blocher, W. C.; Perry, S. L. Complex Coacervate-Based Materials for Biomedicine. Wiley Interdiscip. Rev. Nanomedicine Nanobiotechnology 2017, 9 (4), 76-78. https://doi.org/10.1002/wnan.1442.

(74) Spruijt, E.; Westphal, A. H.; Borst, J. W.; Cohen Stuart, M. A.; Van Der Gucht, J. Binodal Compositions of Polyelectrolyte Complexes. Macromolecules 2010, 43 (15), 6476-6484. https://doi.org/10.1021/ma101031t.

(75) Perry, S. L.; Li, Y.; Priftis, D.; Leon, L.; Tirrell, M. The Effect of Salt on the Complex Coacervation of Vinyl Polyelectrolytes. Polymers (Basel). 2014, 6 (6), 1756-1772. https://doi.org/10.3390/polym6061756.

(76) Liu, Y.; Winter, H. H.; Perry, S. L. Linear Viscoelasticity of Complex Coacervates. 2017, 239, 46-60.

(77) Priftis, D.; Tirrell, M. Phase Behaviour and Complex Coacervation of Aqueous Polypeptide Solutions. Soft Matter 2012, 8 (36), 9396-9405. https://doi.org/10.1039/c2sm25604e.

(78) Kayitmazer, A. B.; Koksal, A. F.; Kilic Iyilik, E. Complex Coacervation of Hyaluronic Acid and Chitosan: Effects of PH, Ionic Strength, Charge Density, Chain Length and the Charge Ratio. Soft Matter 2015, 11 (44), 8605-8612. https://doi.org/10.1039/c5sm01829c.

(79) Jackson, L. S. Microencapsulation in the Food Industry. 2017, No. January 1991.

(80) Schmitt, C.; Turgeon, S. L. Protein / Polysaccharide Complexes and Coacervates in Food Systems. 2011, 167, 63-70. https://doi.org/10.1016/j.cis.2010.10.001.

(81) Turgeon, S. L.; Schmitt, C.; Sanchez, C. Protein - Polysaccharide Complexes and Coacervates. 2007, 12, 166-178. https://doi.org/10.1016/j.cocis.2007.07.007.

(82) Matalanis, A.; Grif, O.; Mcclements, D. J. Food Hydrocolloids Structured Biopolymer-Based Delivery Systems for Encapsulation , Protection , and Release of Lipophilic Compounds. 2011, 25. https://doi.org/10.1016/j.foodhyd.2011.04.014.

(83) Nolles, A.; Westphal, A. H.; Hoop, J. A. De; Fokkink, R. G.; Kleijn, J. M.; Berkel, W. J. H. Van; Borst, J. W. Encapsulation of GFP in Complex Coacervate Core Micelles. 2015. https://doi.org/10.1021/acs.biomac.5b00092. 
(84) Devi, N.; Sarmah, M.; Khatun, B.; Maji, T. K. Encapsulation of Active Ingredients in Polysaccharide - Protein Complex Coacervates. 2017, 239, 136-145.

(85) Black, K. A.; Priftis, D.; Perry, S. L.; Yip, J.; Byun, W. Y.; Tirrell, M. Protein Encapsulation via Polypeptide Complex Coacervation. 2014, 3-6.

(86) Nanoparticles, C. H.; Yen, J.; Ying, H.; Wang, H.; Yin, L.; Uckun, F.; Cheng, J. CD44 Mediated Nonviral Gene Delivery into Human Embryonic Stem. 2016. https://doi.org/10.1021/acsbiomaterials.5b00393.

(87) Online, V. A.; Wang, W.; Xu, Y.; Li, A.; Li, T.; Liu, M.; Ober, C. K.; Kayitmazer, A. B.; Li, L.; Guo, X. RSC Advances Bioadhesive and Its Transition to a SelfHealing. 2015, 66871-66878. https://doi.org/10.1039/c5ra11915d.

(88) Stewart, R. J.; Wang, C. S.; Shao, H. Complex Coacervates as a Foundation for Synthetic Underwater Adhesives. 2011, 167, 85-93. https://doi.org/10.1016/j.cis.2010.10.009.

(89) Fu, J. Driving Forces for Oppositely Charged Polyion Association in Aqueous Solutions: Enthalpic, Entropic, but Not Electrostatic. 2016. https://doi.org/10.1021/jacs.5b11878.

(90) Bucur, C. B.; Sui, Z.; Schlenoff, J. B. Ideal Mixing in Polyelectrolyte Complexes and Multilayers : Entropy Driven Assembly. 2006, 13690-13691.

(91) Fu, J.; Fares, H. M. Ion-Pairing Strength in Polyelectrolyte Complexes. 2017. https://doi.org/10.1021/acs.macromol.6b02445.

(92) Priftis, D.; Leon, L.; Song, Z.; Perry, S. L.; Margossian, K. O.; Tropnikova, A.; Cheng, J.; Tirrell, M. Self-Assembly of ??-Helical Polypeptides Driven by Complex Coacervation. Angew. Chemie - Int. Ed. 2015, 54 (38), 11128-11132. https://doi.org/10.1002/anie.201504861.

(93) Wang, Q.; Schleno, J. B. The Polyelectrolyte Complex/Coacervate Continuum. 2014.

(94) Dimitrios Priftis a, $\Uparrow$; Katie Megley a; Nicolas Laugel a, b; Matthew Tirrell a, 1. Complex Coacervation of Poly(Ethylene-Imine)/Polypeptide Aqueous Solutions: Thermodynamic and Rheological Characterization. J. Colloid Interface Sci. 2013, 398, 39-50.

(95) Du, X.; Dubin, P. L.; Hoagland, D. A.; Sun, L. Protein-Selective Coacervation with Hyaluronic Acid. Biomacromolecules 2014, $15 \quad$ (3), 726-734. https://doi.org/10.1021/bm500041a.

(96) Theron, S. A.; Zussman, E.; Yarin, A. L. Experimental Investigation of the Governing Parameters in the Electrospinning of Polymer Solutions. Polymer (Guildf). 2004, 45 (6), 2017-2030. https://doi.org/10.1016/j.polymer.2004.01.024.

(97) Spruijt, E.; Cohen Stuart, M. A.; Van Der Gucht, J. Linear Viscoelasticity of 
Polyelectrolyte Complex Coacervates. Macromolecules 2013, 46 (4), 1633-1641. https://doi.org/10.1021/ma301730n.

(98) Lawrence, P. G.; Lapitsky, Y. Ionically Cross-Linked Poly(Allylamine) as a Stimulus-Responsive Underwater Adhesive: Ionic Strength and PH Effects. Langmuir 2015, 31 (4), 1564-1574. https://doi.org/10.1021/la504611x.

(99) Miao, J.; Pangule, R. C.; Paskaleva, E. E.; Hwang, E. E.; Kane, R. S.; Linhardt, R. J.; Dordick, J. S. Biomaterials Lysostaphin-Functionalized Cellulose Fi Bers with Antistaphylococcal Activity for Wound Healing Applications. 2011, 32. https://doi.org/10.1016/j.biomaterials.2011.08.080. 